\title{
Synaptic Plasticity in the Amygdala in a Model of Arthritic Pain: Differential Roles of Metabotropic Glutamate Receptors 1 and 5
}

\author{
Volker Neugebauer, ${ }^{1}$ Weidong Li, ${ }^{1}$ Gary C. Bird, ${ }^{1}$ Gautam Bhave, ${ }^{2}$ and Robert W. Gereau IV ${ }^{2}$ \\ ${ }^{1}$ Department of Anatomy and Neurosciences and Marine Biomedical Institute, The University of Texas Medical Branch, Galveston, Texas 77555-1069, and \\ ${ }^{2}$ Division of Neuroscience, Baylor College of Medicine, Houston, Texas 77030
}

\begin{abstract}
Pain has a strong emotional-affective dimension, and the amygdala plays a key role in emotionality. Mechanisms of pain-related changes in the amygdala were studied at the cellular and molecular levels in a model of arthritis pain. The influence of the arthritic condition induced in vivo on synaptic transmission and group I metabotropic glutamate receptor (mGluR1 and mGluR5) function was examined in vitro using whole-cell voltage-clamp recordings of neurons in the central nucleus of the amygdala (CeA). G-protein-coupled mGluRs are implicated in various forms of neuroplasticity as well as in neurological and psychiatric disorders. Synaptic transmission was evoked by electrical stimulation of afferents from the basolateral amygdala (BLA) and the pontine parabrachial (PB) area in brain slices from control (untreated or saline-injected) rats and from arthritic rats. This study shows enhanced synaptic transmission of nociceptivespecific inputs $(\mathrm{PB} \rightarrow \mathrm{CeA}$ synapse) and polymodal sensory inputs (BLA $\rightarrow$ CeA synapse) in the arthritis model. CeA neurons from arthritic rats also developed increased excitability compared with control CeA neurons. Synaptic plasticity in the CeA was accompanied by increased presynaptic mGluR1 function and upregulation of mGluR1 and mGluR5. A selective mGluR1 antagonist reduced transmission in CeA neurons from arthritic animals but not in control neurons, and increased levels of mGluR1 and mGluR5 protein were measured in the $\mathrm{CeA}$ of arthritic rats compared with controls. Our results show that plastic changes in the amygdala in an arthritis model that produces prolonged pain involve a critical switch of presynaptic mGluR1 expression and function.
\end{abstract}

Key words: amygdala; arthritis pain; electrophysiology; metabotropic glutamate receptors; nociception; patch-clamp; plasticity; synaptic transmission

\section{Introduction}

The amygdala plays a key role in the emotional-affective aspects of behavior, the emotional evaluation of sensory stimuli, emotional learning and memory, and related disorders (Davis, 1998; Cahill, 1999; Davidson et al., 1999; Gallagher and Schoenbaum, 1999; Maren, 1999; Aggleton, 2000; LeDoux, 2000; Rasia-Filho et al., 2000). The amygdala is also implicated in the emotionalaffective component of pain (Bernard and Bandler, 1998; Manning et al., 2001; Schneider et al., 2001; Neugebauer and Li, 2002).

The amygdala exhibits a high degree of plasticity in models of tetanic, pharmacologically induced, and behavioral long-term modification of synaptic transmission (McKernan and ShinnickGallagher, 1997; Neugebauer et al., 1997a, 2000; Maren, 1999; Wang and Gean, 1999; LeDoux, 2000; Martin et al., 2000; Bauer et al., 2001; Blair et al., 2001; Lin et al., 2001). Such neuroplasticity is believed to be involved in associative learning and in certain neurological and psychiatric disorders.

Received April 10, 2002; revised 0ct. 9, 2002; accepted 0ct. 14, 2002.

This work was supported by John Sealy Memorial Endowment Fund for Biomedical Research 2528-99 (V.N.) and National Institutes of Health Grants NS38261 (V.N.) and MH60230 (R.W.G.). G.B. is a McNair scholar of the Baylor College of Medicine Medical Scientist Training Program. We thank Dr. William D. Willis for continued generous support and critical reading of and helpful comments on this manuscript. We also thank Vicki Wilson for superb secretarial assistance.

Correspondence should be addressed to Dr. Volker Neugebauer, Department of Anatomy and Neurosciences and Marine Biomedical Institute, The University of Texas Medical Branch, 301 University Boulevard, Galveston, TX775551069. E-mail:voneugeb@utmb.edu.

Copyright $\odot 2002$ Society for Neuroscience $\quad 0270-6474 / 02 / 220052-12 \$ 15.00 / 0$
The amygdala receives purely nociceptive information through the spino-parabrachio-amygdaloid pain pathway, which connects the pontine parabrachial area and spinal cord with the central nucleus of the amygdala (CeA) (Bernard et al., 1993; Jasmin et al., 1997; Buritova et al., 1998) (see Fig. 1). Polymodal sensory, including nociceptive, information reaches the amygdala from thalamic and cortical areas through connections with the lateral and basolateral amygdaloid nuclei, which then project to the CeA, the output nucleus for major amygdala functions (Pitkanen et al., 1997; Doron and LeDoux, 1999; Linke et al., 1999; Shi and Davis, 1999; LeDoux, 2000; Smith et al., 2000) (see Fig. 1).

Accumulating evidence implicates the amygdala in pain processing and modulation. Electrical stimulation of the amygdala elicits vocalizations that are accompanied by emotional reactions in monkeys (Jurgens et al., 1967; Jurgens, 1982). Lesions or temporary inactivation of the amygdala decrease higher integrated emotional pain responses without affecting normal behavior or baseline nociceptive responses (Charpentier, 1967; Calvino et al., 1982; Helmstetter, 1992; Maier et al., 1993; Fox and Sorenson, 1994; Watkins et al., 1998; Borszcz, 1999; Tershner and Helmstetter, 2000). Single-unit recordings in anesthetized rats defined the capsular division of the CeA as the "nociceptive amygdala," because the vast majority of these neurons respond exclusively or preferentially to painful stimuli (Bernard et al., 1992; Neugebauer and $\mathrm{Li}, 2002$ ).

The role of the amygdala in prolonged, and chronic pain is mostly unknown. This study is the first to address cellular and 
molecular mechanisms of synaptic plasticity in the amygdala in a well established model of arthritic pain arising from a localized inflammation of one knee joint (Neugebauer et al., 1993, 1994, $1995,1996)$. We focus on group I metabotropic glutamate receptors (mGluRs), which are involved in neuroplasticity associated with normal brain functions as well as in neurological and psychiatric disorders (Fundytus, 2001; Neugebauer, 2001a, 2002). Group I mGluRs comprise mGluR1 and mGluR5 subtypes. These couple through $\mathrm{G}_{\mathrm{q} / 11}$-proteins to the activation of phospholipase $\mathrm{C}$ and protein kinase $\mathrm{C}$, and they also regulate various other signal transduction pathways. Accumulating evidence suggests an important role of mGluRs in pain processing (Fundytus, 2001; Karim et al., 2001; Neugebauer, 2001a,b; Neugebauer, 2002; Neugebauer and Carlton, 2002; Varney and Gereau, 2002).

\section{Materials and Methods}

Electrophysiological and biochemical data were obtained from control rats (untreated normal rats and saline-injected "sham" rats) and rats with monoarthritis (6-8 hr after induction). Male Sprague Dawley rats (110$250 \mathrm{gm})$ were individually housed in standard plastic boxes $(40 \times 20 \mathrm{~cm})$ in a temperature-controlled room and maintained on a $12 \mathrm{hr}$ day/night cycle. Standard laboratory chow and tap water were available ad libitum. On the day of the experiment, rats were transferred from the animal facility and allowed to acclimate to the laboratory for at least $1 \mathrm{hr}$.

\section{Arthritis pain model}

In one group of rats ("arthritis"), arthritis was induced in one knee joint as described in detail previously (Neugebauer et al., 1989, 1993, 1994, 1995, 1996; Neugebauer and Schaible, 1990). A kaolin suspension (4\%, $80-100 \mu \mathrm{l}$ ) was slowly injected into the joint cavity through the patellar ligament with a syringe and needle $(1 \mathrm{ml}, 25 \mathrm{G} 5 / 8)$. After repetitive flexions and extensions of the knee for $15 \mathrm{~min}$, a carrageenan solution $(2 \%$, $80-100 \mu \mathrm{l})$ was injected into the knee joint cavity, and the leg was flexed and extended for another $5 \mathrm{~min}$. This treatment paradigm reliably leads to localized inflammation and swelling of the injected knee within 1-3 hr. The inflammation persists for up to 2 weeks. It does not spread systemically (Neugebauer et al., 1989, 1993, 1994, 1995, 1996; Neugebauer and Schaible, 1990; Min et al., 2001).

Another group of rats ("shams") received injections of a sterile physiological saline solution into one knee joint similar to the kaolin and carrageenan injections of the arthritis group. The knee joint was rhythmically flexed and extended as in the arthritis group (see above). The intra-articular saline injection caused a temporary swelling of the knee joint, which did not persist beyond $2 \mathrm{hr}$ after injection.

The third group of rats ("normal") did not receive any injections but was kept under the same conditions as the arthritis and sham rats before brain slices were obtained for electrophysiological and molecular studies.

\section{Behavioral tests}

Evoked and spontaneous pain-related behavior was tested in rats from which brain slices were obtained for electrophysiology and Western blot analysis. Behavioral data were measured in control rats, which consisted of untreated normal rats and shams, and arthritic rats.

Evoked behavior. Hindlimb withdrawal and vocalization thresholds were measured and determined as follows: mechanical stimuli of gradually increasing intensity (steps of $50 \mathrm{gm} / 30 \mathrm{~mm}^{2}$ ) were applied to the hindpaw by means of a forceps with a force transducer, whose calibrated output was amplified and displayed in $g$ on an liquid crystal display screen. Threshold was defined as the minimum stimulus intensity that evoked withdrawal of the hindlimb or vocalization. The threshold stimulus intensity was then tested again three times to verify the presence of the withdrawal reflex or vocalization in at least $50 \%$ of trials.

Spontaneous behavior. Exploratory behavior was measured using an activity box, which monitors exploratory activity in terms of the frequency at which the animal interrupts one of six beams of UV light over $45 \mathrm{~min}$. A computer tracked the activity and provided a report of exploratory activity over time in terms of parameters such as entries, distance traveled, and time spent resting.

\section{Electrophysiology}

Whole-cell voltage-clamp recordings were made from CeA neurons in brain slices from control and arthritic rats $(6-8 \mathrm{hr}$ after induction of arthritis). Monosynaptic EPSCs were evoked at the parabrachial $(\mathrm{PB}) \rightarrow$ CeA synapse (nociceptive-specific input) and the basolateral amygdala (BLA) $\rightarrow$ CeA synapse (polymodal sensory, including nociceptive, inputs) (Fig. 1). Drugs dissolved in artificial CSF (ACSF) were applied by superfusion. ACSF contained (in $\mathrm{mM}$ ): $117 \mathrm{NaCl}, 4.7 \mathrm{KCl}, 1.2$ $\mathrm{NaH}_{2} \mathrm{PO}_{4}, 2.5 \mathrm{CaCl}_{2}, 1.2 \mathrm{MgCl}_{2}, 25 \mathrm{NaHCO}_{3}$, and 11 glucose.

Amygdala slice preparation. Brain slices containing the CeA were obtained as previously described (Neugebauer et al. 1997a, 2000) (see Fig. 1). Rats were decapitated, and the brains quickly dissected out and blocked in cold $\left(4^{\circ} \mathrm{C}\right)$ ACSF (see above). ACSF was oxygenated and equilibrated to $\mathrm{pH} 7.4$ with a mixture of $95 \% \mathrm{O}_{2}$ and $5 \% \mathrm{CO}_{2}$. Coronal brain slices $(350-500 \mu \mathrm{m})$ were prepared using a Vibroslice (Camden Instruments, London, UK). After incubation in ACSF at room temperature $\left(21^{\circ} \mathrm{C}\right)$ for at least $1 \mathrm{hr}$, a single brain slice was transferred to the recording chamber and submerged in $\operatorname{ACSF}\left(31 \pm 1^{\circ} \mathrm{C}\right)$, which superfused the slice at $\sim 2 \mathrm{ml} / \mathrm{min}$.

Whole-cell patch-clamp recording. Whole-cell recordings using the "blind" patch technique (Blanton et al., 1989) or differential interference contrast (DIC)-enhanced infrared (IR) videomicroscopy (Dodt and Zieglgansberger, 1990, 1998) (see Fig. 1) were obtained from CeA neurons using patch electrodes made from $1.5 \mathrm{~mm}$ borosilicate glass capillaries (1.5 mm outer diameter, $1.12 \mathrm{~mm}$ inner diameter; Drummond, Broomall, PA) pulled on a Flaming-Brown micropipette puller (P-80/ PC; Sutter Instrument Co., Novato, CA). Recording electrodes were positioned in the central medial and lateral capsular divisions of the CeA under visual control. The boundaries of the CeA were discerned under light microscopy (see Fig. 1); each slice was matched with the corresponding level of Paxinos and Watson (1998). The internal solution of the recording electrodes ( $3-5 \mathrm{M} \Omega$ tip resistance) contained (in mM): 122 K-gluconate, $5 \mathrm{NaCl}, 0.3 \mathrm{CaCl}_{2}, 2 \mathrm{MgCl}_{2}, 1$ EGTA, $10 \mathrm{HEPES}, 5 \mathrm{Na}_{2}$ ATP, and $0.4 \mathrm{Na}_{3}$-GTP, pH was adjusted to $7.2-7.3$ with $\mathrm{KOH}$ and osmolarity to $280 \mathrm{mOsm} / \mathrm{kg}$ with sucrose.

After tight $(>2 G \Omega)$ seals were formed and the whole-cell configuration was obtained, neurons were included in the sample if the resting membrane potential was more negative than $-50 \mathrm{mV}$, and action potentials overshooting $0 \mathrm{mV}$ were evoked by direct cathodal stimulation. Voltage and current signals were low-pass-filtered at $1 \mathrm{kHz}$ with a dual four-pole Bessel filter (Warner Instrument Corp., Hamden, CT), digitized at $5 \mathrm{kHz}$ (Digidata 1200 interface; Axon Instruments, Foster City, CA), and stored on a computer (Gateway Performance Pentium III). Data were also continuously recorded on a pen chart recorder (3400; Gould Instruments, Valley View, OH). Evoked potential and evoked current data were acquired and analyzed using pCLAMP8 software (Axon Instruments). Discontinuous single-electrode voltage-clamp recordings were acquired using an Axoclamp-2B amplifier (Axon Instruments) with a switching frequency of $5-6 \mathrm{kHz}$ ( $30 \%$ duty cycle), gain of $3-8 \mathrm{nA} / \mathrm{mV}$, and time constant of $20 \mathrm{msec}$. Phase shift and the antialias filter were optimized. The head stage voltage was monitored continuously on a digital oscilloscope (Gould 400) to ensure precise performance of the amplifier. Neurons were voltage-clamped at $-60 \mathrm{mV}$.

Synaptic stimulation. The CeA represents the major output nucleus of the amygdala and processes information from other amygdala nuclei and from widespread brain areas. We studied two lines of input to the CeA: the BLA $\rightarrow$ CeA synapse and the pontine $\mathrm{PB} \rightarrow \mathrm{CeA}$ synapse (see introductory remarks and Fig. 1). Using two concentric bipolar stimulating electrodes (Kopf Instruments) of $22 \mathrm{k} \Omega$ resistance, EPSCs were evoked in CeA neurons by electrical stimulation (using an S88 stimulator; Grass Instruments) of the two afferent synapses to the CeA (see Fig. 1): the $\mathrm{PB} \rightarrow$ CeA synapse, which provides nociceptive inputs from the spinal cord and brainstem (PB; Bernard et al., 1993; Harrigan et al., 1994; Alheid et al., 1995), and the BLA-CeA synapse, which provides highly integrated polymodal sensory, including nociceptive, information from thalamic and cortical areas (see introductory remarks). For stimulation of the $\mathrm{PB}$, the electrode was positioned under microscopic control on the fibers dorsomedial to the CeA and ventral to but outside the caudateputamen (Bernard et al., 1993). Electrical stimuli (150 $\mu$ sec square-wave 
pulses) were delivered at frequencies $<0.25 \mathrm{~Hz}$. Thresholds for EPSCs and spiking were defined as the respective intensity that evoked a response in at least 5 of 10 trials with mean amplitude determined from the 10 trial stimulations. Input-output relationships were obtained by increasing the stimulus intensity in $50 \mu \mathrm{A}$ steps. For evaluation of a drug effect on synaptically evoked responses, the stimulus intensity was adjusted to $75-80 \%$ of the intensity required for orthodromic spike generation.

Paired-pulse facilitation. Paired-pulse facilitation (PPF) is being used to distinguish presynaptic versus postsynaptic mechanisms in the CNS (McKernan and Shinnick-Gallagher, 1997, and references therein). Two orthodromic synaptic stimuli of equal intensity were applied at varying intervals, and the resulting EPSCs were recorded. PPF refers to the phenomenon that the amplitude of the second EPSC is usually larger than the initial EPSC if the interstimulus interval is sufficiently small. In whole-cell voltage clamp, peak amplitudes were measured as the difference between the current level before the stimulus artifact and the peak of the EPSC. PPF (see Fig. 5) is calculated as [(EPSC2 - EPSC1)/EPSC1] $\times$ 100 (see McKernan and Shinnick-Gallagher, 1997). If a drug increases neurotransmitter release, PPF is reduced, whereas enhanced PPF would indicate decreased neurotransmitter release. Any alterations in PPF suggest a presynaptic site of action. PPF was tested before and during application of mGluR agonists.

Drugs. The following drugs were used: 2-amino-5-phosphonopentanoicacid(AP-5), 2-chloro-5-hydroxyphenyl-glycine(CHPG), 6-cyano7-nitroquinoxaline-2,3-dione(CNQX),7-(hydroxyimino)cyclopropa[b] chromen-1a-carboxylate ethyl ester (CPCCOEt), (S)-3,5-dihydroxyphenylglycine (DHPG), and 2-methyl-6-(phenylethynyl)pyridine (MPEP); these were purchased from Tocris Cookson (Bristol, UK). All drugs were applied by gravity-driven superfusion in the ACSF. Solution flow into the recording chamber ( $1 \mathrm{ml}$ volume) was controlled with a three-way stopcock. Drug applications were for at least 8-10 min (agonists) and 10-15 min (antagonists) in duration to establish equilibrium in the tissue.

\section{Quantitative immunoblotting}

Two to three $500 \mu \mathrm{m}$ amygdala slices from control or arthritic rats $(6-8$ $\mathrm{hr}$ after induction) were homogenized in $1 \mathrm{ml}$ of homogenization buffer (in mM: 320 sucrose, 10 HEPES-Na, pH 7.5, and 1 EDTA-Na, pH 8) using eight strokes of a glass-Teflon motorized homogenizer. The homogenate was centrifuged at $1500 \times g$ for $5 \mathrm{~min}$ to remove nuclei and debris and then centrifuged at $100,000 \times g$ for $30 \mathrm{~min}$ in a TLA100.2 rotor to pellet postnuclear membranes. The pellet was resuspended in homogenization buffer and solubilized with an equal volume of either $2 \times$ sample buffer (100 mm Tris-Cl, pH 6.8, 4\% SDS, 20\% glycerol, and $0.02 \%$ bromophenol blue) for SDS-PAGE or $4 \%$ SDS for protein quantitation. A BCA assay (Pierce, Rockford, IL) using bovine serum albumin as a standard was used to determine protein concentration.

Ten micrograms of membrane protein were loaded onto a polyacrylamide gel and transferred to a nitrocellulose membrane using a semidry transfer apparatus. The blots were blocked in Tris-buffered saline with Tween 20 (TBST; $150 \mathrm{~mm} \mathrm{NaCl}, 50 \mathrm{~mm}$ Tris-Cl, pH 7.5, and $0.05 \%$ Tween 20) and 5\% milk for $1 \mathrm{hr}$ at room temperature, incubated for $1 \mathrm{hr}$ in either mGluR1a antibody (1:1000; Upstate Biotechnology, Lake Placid, NY) or mGluR5 antibody (1:2000; Upstate Biotechnology) diluted in TBST and 5\% nonfat dry milk, washed four times with TBST, incubated for $1 \mathrm{hr}$ in ${ }^{125}$ I-coupled donkey anti-rabbit secondary antibody $(0.2 \mu \mathrm{Ci} / \mathrm{ml}$; Amersham Biosciences, Piscataway, NJ) diluted in TBST and 5\% milk, and finally washed four times with TBST.

Signals were detected and densitized using a Cyclone phosphorimager and Optiquant acquisition and analysis software (Packard Instrument Co., Meriden, CT). All statistical comparisons were done using a log transformation of immunoreactivity to yield ratios with normal distributions for parametric statistics (Robakiewicz and Ryder, 2000).

\section{Data analysis}

Electrophysiology. Membrane properties, EPSC threshold, spike threshold, input-output relationships, and drug effects were measured in neurons from control rats and neurons from arthritic rats. The Mann-Whitney $U$ test (GraphPad Prism 3.0) was used to compare membrane properties. Differences in EPSC and spike thresholds were evaluated for statistical significance using an unpaired $t$ test (GraphPad Prism 3.0). Input-output relationships, drug effects on paired pulse facilitation, and concentration-response relationships of drug effects were analyzed using a two-way ANOVA followed by Bonferroni post-tests (GraphPad Prism 3.0). $\mathrm{EC}_{50}$ values were calculated from sigmoid curves fitted to the cumulative concentration-response data by nonlinear regression using the following formula: $y=A+(B-A) /\left[1+\left(10^{C} / 10^{X}\right)^{D}\right]$, where $A$ is bottom plateau, $B$ is top plateau, $C$ is $\log \left(\mathrm{EC}_{50}\right)$, and $D$ is slope coefficient (GraphPad Prism 3.0). Effects of individual drug concentrations were compared between control and arthritis using unpaired $t$ tests. Using the linear curve fit function of pCLAMP8 software (Axon Instruments), slope conductance (in nanosiemens) in the absence and presence of drugs was calculated from the linear portion of the $I-V$ relationships recorded in voltage-clamp mode. Concentration-dependent drugrelated changes of slope conductance in neurons from arthritic rats and in control neurons were analyzed using post hoc $t$ tests after repeated measures ANOVA (GraphPad Prism 3.0). All averaged values are given as mean \pm SEM. Statistical significance was accepted at the $p<0.05$.

Quantitative Western blotting. Densitometry of mGluRla and mGluR5 immunoreactivity in arthritic rats was compared with that of control rats using a one-sample $t$ test. Ipsilateral and contralateral sides were compared with a paired $t$ test. All averaged values are given as mean \pm SEM. Statistical significance was accepted at $p<0.05$.

\section{Results}

Kaolin- and carrageenan-induced monoarthritis caused swelling of the injected but not the contralateral knee joint within 1-3 hr. The inflammation reached a maximum plateau after $4-6 \mathrm{hr}$ and lasted for at least $24 \mathrm{hr}$ (Fig. 1). Intra-articular saline injections caused only a temporary swelling of the knee, which did not last $>2 \mathrm{hr}$ (Fig. 1). This monoarthritis resulted in significantly decreased hindlimb withdrawal and vocalization thresholds to mechanical stimuli $(n=10)$ and was associated with reduced exploratory behavior $(n=13)$ compared with control rats $(n=13)$.

\section{Synaptic plasticity and altered membrane properties in CeA neurons in the arthritis pain model}

Whole-cell voltage-clamp recordings of CeA neurons were made in brain slices from control rats (untreated normal rats or salineinjected shams) and from rats in which the arthritis had been induced in one knee joint by intra-articular injections of kaolin and carrageenan $6-8 \mathrm{hr}$ before. Because no obvious differences in membrane properties, synaptic transmission, and effects of mGluR agonists and antagonists were measured between neurons from untreated rats and neurons from saline-injected shams, the data were pooled and termed "controls."

Synaptic plasticity in the amygdala has been shown to underlie a number of long-term behavioral modifications in the kindling model of epilepsy, chronic cocaine model of drug addiction, and models of conditioned fear and associative learning [lateral amygdala (LA)-BLA: LeDoux et al., 1990; Rainnie et al., 1992; McKernan and Shinnick-Gallagher, 1997; Neugebauer et al., 1997a; Wang and Gean, 1999; Lin et al., 2000, Bauer et al., 2001; Blair et al., 2001; Lin et al., 2001] (CeA: Neugebauer et al., 2000; Nader et al., 2001). To test whether the arthritic pain behavior is associated with synaptic plasticity in the "nociceptive amygdala" (Bourgeais et al., 2001; Neugebauer and Li, 2002), we performed whole-cell patch-clamp recordings of membrane properties and synaptic transmission in CeA neurons recorded in brain slices obtained from control (normal and sham) rats and arthritic rats.

CeA neurons from arthritic animals (6-8 hr after induction) showed several characteristics that distinguished them from neurons in brain slices from control animals (Table 1, Fig. 2). The resting membrane potential of $\mathrm{CeA}$ neurons was, on average, 


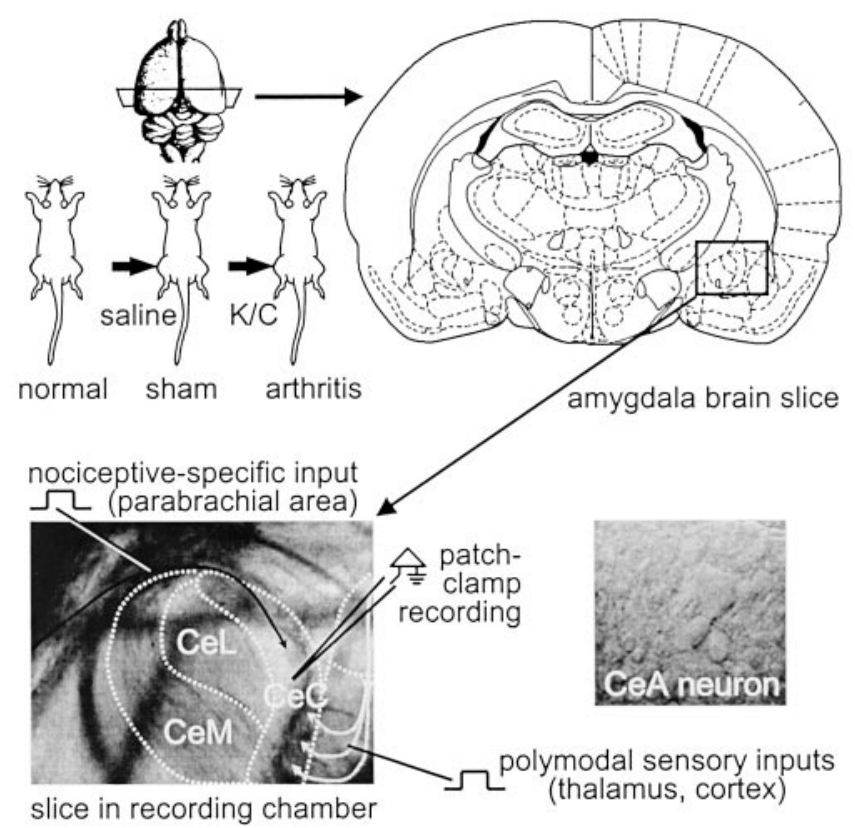

\section{Development of arthritis}
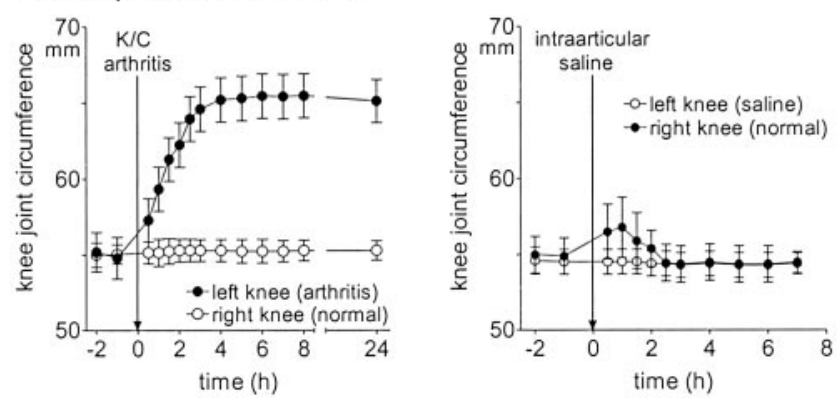

Figure 1. Experimental setup, design of electrophysiological studies, and time course of arthritis pain model. Coronal brain slices containing the amygdala were obtained from control (untreated normal and saline-injected sham) rats and from arthritic rats $6-8 \mathrm{hr}$ after injections of kaolin and carrageenan (K/C) into one knee joint. Under microscopic control, the patch-clamp electrode was positioned in the "nociceptive amygdala," which is the lateral capsular part ( $\mathrm{CeC}$ ) of the CeA contralateral to the arthritis (cf. Bourgeais et al., 2001; Neugebauer and Li, 2002). Two stimulation electrodes were arranged for synaptic stimulation of afferent fibers from the pontine PB area providing nociceptive information to the CeA (left; Bernard et al., 1993) and inputs from the lateral-basolateral amygdala (right) providing polymodal information to the CeA from thalamic and cortical areas (part of the netting below the slice can be seen). Individual amygdala neurons were visualized and patched using DIC-enhanced infrared IR videomicroscopy (inset, CeA neurons and "dimple" caused by the patch electrode approaching from the bottom right). (eM, CeL, Medial and lateral subdivisions of the CeA, respectively. Intra-articular injections of kaolin and carrageenan cause the progressive, persistent swelling of the injected knee joint but not the uninjected contralateral knee joint ( $n=35$; graph on bottom left). Intra-articular saline injections produce only a temporary swelling of the injected knee ( $n=12$; graph on bottom right).

significantly depolarized (Table $1 ; p<0.001$; Mann-Whitney $U$ test). Compared with control neurons, neurons from arthritic rats also had a lower threshold and higher frequency of action potentials generated by direct depolarizing current pulses injected via the recording electrode in current-clamp mode (see individual examples in Fig. $2 A, B$ ). Increased action potential firing rate (Fig. $2 C ; p<0.0001 ; F_{(1,448)}=34.25$; two-way ANOVA) and membrane potentials at which action potentials were evoked by intracellular current injections (Table 1 ; $p<0.05$; MannWhitney $U$ test) were significantly different. Current-clamp recordings showed that the input resistance of CeA neurons from arthritic rats was significantly decreased compared with control neurons ( $p<0.001$; Mann-Whitney $U$ test; Table 1 ). Input resistance was calculated from the slope of the linear portion of the $I-V$ curve. Transient current pulses $(500 \mathrm{msec})$ were injected via the recording electrode in $50 \mathrm{pA}$ increments from a holding potential of $-60 \mathrm{mV}$. $I-V$ curves (Fig. $2 F$ ) were obtained by plotting steady-state voltage changes against the amplitudes of current injections (see individual examples in Fig. 2D,E). Accordingly, voltage-clamp data showed that the average slope conductance calculated from the linear portion of the $I-V$ relationship was greater in neurons from arthritic animals than in control neurons from normal animals (Table $1 ; p<0.001$; Mann-Whitney $U$ test). These data suggest altered intrinsic membrane properties of CeA neurons in the arthritis pain model.

In addition to the enhanced excitability of CeA neurons in the arthritis pain model, we also observed enhanced synaptic transmission at the nociceptive $\mathrm{PB} \rightarrow \mathrm{CeA}$ synapse and the polymodal $\mathrm{BLA} \rightarrow \mathrm{CeA}$ synapse (see introductory remarks) in CeA neurons from arthritic rats compared with control CeA neurons (Fig. 3). Monosynaptic EPSCs with progressively larger amplitudes were evoked by electrical stimulation with increasing intensities $(\mathrm{BLA} \rightarrow \mathrm{CeA}$ synapse, Fig. $3 A, C, E ; \mathrm{PB} \rightarrow \mathrm{CeA}$ synapse, Fig. $3 B, D, F)$. Compared with control neurons (Fig. $3 A, B$ ), synaptic transmission was enhanced in CeA neurons recorded in brain slices from arthritic rats (6-8 hr after induction of arthritis) (Fig. $3 C, D)$. In arthritis, evoked monosynaptic EPSCs had larger amplitudes, and the threshold for orthodromic spike generation was lower at both synapses, whereas a lower EPSC threshold was recorded only at the BLA $\rightarrow$ CeA synapse (Table 1 ). Consistent with the $\mathrm{PB} \rightarrow \mathrm{CeA}$ synapse providing high-threshold nociceptive $\mathrm{PB}$ input (see introductory remarks), the major change of synaptic transmission was with high-intensity stimulation, whereas synaptic transmission at the polymodal BLA $\rightarrow$ CeA synapse was enhanced over a wide range of low- and high-intensity stimulation. The fast monosynaptic EPSCs at both the BLA $\rightarrow$ CeA synapse and the $\mathrm{PB} \rightarrow \mathrm{CeA}$ synapse were completely blocked in the presence of NMDA and non-NMDA receptor antagonists (AP-5, 50 $\mu \mathrm{M}$; CNQX, $30 \mu \mathrm{M}$, respectively) in CeA neurons from control animals $(n=12)$ and in the arthritis pain model $(n=8)$, suggesting that basal synaptic transmission at these synapses is mediated entirely by ionotropic glutamate receptors.

Input-output relationships were obtained by measuring EPSC peak amplitude (picoamperes) as a function of afferent fiber stimulus intensity (microamperes) for each neuron (see examples in Fig. $3 A-D$ ). The comparison of input-output relationships between neurons from control rats $(n=36$; normal uninjected rats, $n=26$; saline-injected shams, $n=10)$ and neurons from arthritic rats $(n=20)$ showed significant differences in synaptic transmission in arthritis at both synapses (Fig. 3E,F; two-way ANOVA followed by Bonferroni post-tests). At the $\mathrm{BLA} \rightarrow \mathrm{CeA}$ synapse, the arthritis led to a significant leftward shift of the curves (Fig. 3E) and also lowered the thresholds for evoked EPSCs and orthodromic spike generation (Table 1). The inputoutput relationship measured at the $\mathrm{PB} \rightarrow \mathrm{CeA}$ synapse had a steeper slope, resulting in an upward shift at higher stimulus intensities in CeA neurons from arthritic rats compared with control neurons (Fig. 3F). The spike threshold, but not the EPSC threshold, was also altered at the $\mathrm{PB} \rightarrow$ CeA synapse (Table 1 ).

\section{Differential roles of mGluR 1 and $\mathrm{mGluR} 5$ in synaptic plasticity in the arthritis pain model}

Group I mGluRs, which consist of mGluR1 and mGluR5 subtypes, play important roles in nociceptive plasticity in the periph- 
Table 1. Altered membrane properties and synaptic transmission in CeA neurons in the arthritis model of prolonged pain

\begin{tabular}{|c|c|c|c|c|}
\hline & Control (normal and shams) & & Arthritis & \\
\hline Resting membrane potential (mV) & $-62.8 \pm 0.6(n=62)$ & & $-57.4 \pm 0.8^{*}(n=21)$ & \\
\hline Input resistance (in current clamp) (M $\Omega$ ) & $144.3 \pm 5.3(n=62)$ & & $99.9 \pm 6.4^{*}(n=21)$ & \\
\hline Slope conductance (in voltage clamp) (nS) & $7.7 \pm 0.3(n=62)$ & & $11.2 \pm 0.3^{*}(n=21)$ & \\
\hline $\begin{array}{l}\text { Action potential threshold (action potentials } \\
\text { generated by depolarizing current injection) (mV) }\end{array}$ & $-38.1 \pm 1.5(n=45)$ & & $-45.3 \pm 2.5^{* *}(n=21)$ & \\
\hline Synapse & $\mathrm{BLA} \rightarrow \mathrm{CeA}$ & $\mathrm{PB} \rightarrow \mathrm{CeA}$ & $\mathrm{BLA} \rightarrow \mathrm{CeA}$ & $\mathrm{PB} \rightarrow \mathrm{CeA}$ \\
\hline EPSC threshold $(\mu \mathrm{A})$ & $88 \pm 11(n=36)$ & $132 \pm 10(n=36)$ & $40 \pm 13^{* * *}(n=20)$ & $110 \pm 13(n=20)$ \\
\hline Spike threshold $(\mu \mathrm{A})$ & $377 \pm 33(n=36)$ & $475 \pm 41(n=36)$ & $498 \pm 45^{* * * *}(n=20)$ & $610 \pm 52^{* * * *}(n=20)$ \\
\hline
\end{tabular}

Control neurons were recorded in brain slices from untreated normal rats and saline-injected shams; neurons in the arthritis pain model were recorded in brain slices obtained from arthritic rats 6 - $8 \mathrm{hr}$ after induction.

${ }^{* *} p<0.05,{ }^{*} p<0.001$; compared with control neurons, Mann-Whitney $U$ test; ${ }^{* * *} p<0.05,{ }^{* * *} p<0.01$; compared with control neurons, unpaired $t$ test.

eral nervous system and the spinal cord and have been proposed as novel targets for pain relief (Fundytus, 2001; Karim et al., 2001; Neugebauer, 2001a,b; Gasparini et al., 2002; Neugebauer, 2002; Neugebauer and Carlton, 2002; Varney and Gereau, 2002). The role of mGluRs in the brain, however, in prolonged, and chronic pain states are for the most part unknown. Accumulating evidence suggests a role of mGluRs in the amygdala in synaptic plasticity associated with behavioral modifications (Holmes et al., 1996; Neugebauer et al., 1997a,b, 2000; Masugi et al., 1999; Keele et al., 2000; Lin et al., 2000). Thus, it is conceivable that mGluRs also contribute to pain-related synaptic plasticity in the amygdala. We tested this hypothesis using selective group I agonists and antagonists to analyze changes of receptor function in the arthritis pain model.

\section{Agonists}

We tested whether group I mGluR receptor sensitivity was altered in CeA neurons from arthritic rats compared with control neurons from normal and saline-injected sham rats. In control neurons, a group I mGluR agonist, DHPG, which can activate both mGluR1 and mGluR5 subtypes, potentiated the peak amplitude of monosynaptic EPSCs evoked at the $\mathrm{PB} \rightarrow \mathrm{CeA}$ and $\mathrm{BLA} \rightarrow \mathrm{CeA}$ synapses. This effect was mimicked by a selective mGluR5 agonist, CHPG, which produced similar maximum effects. Figure $4 A$ shows the effects of the group I agonists on EPSCs evoked at the $\mathrm{PB} \rightarrow \mathrm{CeA}$ synapse in one CeA neuron in a brain slice from a normal animal. In CeA neurons from arthritic animals, DHPG more potently potentiated evoked EPSCs, whereas the effects of CHPG were unchanged. Figure $4 B$ shows the effects of DHPG and CHPG at the $\mathrm{PB} \rightarrow \mathrm{CeA}$ synapse in one CeA neuron recorded in a brain slice from an arthritic rat. Drug effects started after superfusing the brain slices for 2-3 min and increased further until a plateau effect was observed at 6-10 min of drug application. Drug effects reported in this study were measured at 8-10 min.

Analysis of the cumulative concentration-response relationships in CeA neurons from control and arthritic animals revealed that DHPG was more potent in arthritis $\left(\mathrm{EC}_{50}, 3.4 \mathrm{nM} ; n=11\right)$ (Fig. 4C, filled circles) than under normal conditions $\left(\mathrm{EC}_{50}, 25.9\right.$ nM; $n=12$ ) (Fig. 4C, open circles), whereas the potency of CHPG did not change significantly (normal: $\mathrm{EC}_{50}, 1.2 \mu \mathrm{M} ; n=9$; Fig. $4 D$, open symbols; arthritis: $\mathrm{EC}_{50}, 0.9 \mu \mathrm{M} ; n=8$; Fig. $4 D$, filled symbols; $p>0.05 ; F_{(1,75)}=0.64$; two-way ANOVA). Concentration-response relationships for DHPG in CeA neurons from control and arthritic rats were significantly different $(p<0.05$; $F_{(1,84)}=4.09$; two-way ANOVA). These data suggest that under normal conditions, the potentiating effects of group I mGluR activation are mediated through mGluR5, whereas the enhanced effects of group I mGluR activation in arthritis involve recruitment or enhanced receptor sensitivity of mGluR1.

The potentiating effects of DHPG $(100 \mathrm{nM})$ in control neu- rons were mostly blocked by a selective mGluR5 antagonist (MPEP, $1 \mu \mathrm{M} ; n=4$ ), whereas a selective mGluR1 antagonist (CPCCOEt, $10 \mu \mathrm{M})$ had only a little effect $(n=4)$. In the arthritis pain model, however, both CPCCOEt $(10 \mu \mathrm{M} ; n=3)$ and MPEP ( $1 \mu \mathrm{M} ; n=3)$ strongly reduced the potentiation by DHPG (100 $\mathrm{nM})$, suggesting a change of mGluR1 involvement in group I mGluR function in the arthritis pain model.

Similar but less pronounced changes of DHPG effects in arthritis were measured at the $\mathrm{BLA} \rightarrow \mathrm{CeA}$ synapse (control: $\mathrm{EC}_{50}$, $7.9 \mathrm{~nm} ; n=12$; arthritis: $\mathrm{EC}_{50}, 3.7 \mathrm{nM} ; n=11 ; p<0.05 ; F_{(1.84)}=$ 4.23; two-way ANOVA; data not shown), suggesting a closer association of mGluR1 with arthritis-related changes at the nociceptive $\mathrm{PB} \rightarrow \mathrm{CeA}$ synapse than the polymodal BLA $\rightarrow$ CeA synapse. The potency of CHPG at the BLA $\rightarrow$ CeA synapse remained mostly unchanged in the arthritis pain model (normal: $\mathrm{EC}_{50}, 0.4$ $\mu \mathrm{M} ; n=6$; arthritis: $\mathrm{EC}_{50}, 0.5 \mu \mathrm{M} ; n=5$; data not shown).

To examine whether enhanced presynaptic transmitter release contributed to the synaptic potentiation by group I mGluR agonists, we analyzed the effect of DHPG on PPF (see Materials and Methods) in CeA neurons. PPF refers to the phenomenon that the amplitude of the second of two EPSCs evoked by synaptic stimulation of equal magnitude is usually larger than the initial EPSC if the interstimulus interval is sufficiently small. If a drug increases neurotransmitter release, PPF is reduced, whereas enhanced PPF would indicate decreased neurotransmitter release. Any alterations in PPF suggest a presynaptic site of action (see McKernan and Shinnick-Gallagher, 1997). Figure 5 shows that DHPG (100 nM; thick lines) reduced PPF (50 msec interstimulus intervals) in a CeA neuron from a normal rat (Fig. 5A) and in another CeA neuron from an arthritic rat (Fig. 5B). The initial EPSC were potentiated by DHPG in both neurons as shown before (Fig. 4). The reduction of PPF by DHPG was statistically significant in CeA neurons from normal rats (Fig. $5 C ; n=6 ; p<$ $0.0001 ; F_{(1,80)}=62.23$; two-way ANOVA) and in CeA neurons from arthritic rats (Fig. $5 D ; n=5 ; p<0.0001 ; F_{(1,64)}=90.84$; two-way ANOVA).

Consistent with our PPF studies suggesting presynaptic mechanism(s) of group I mGluR-mediated synaptic potentiation, we did not find any evidence that the effects of DHPG and CHPG on synaptic transmission were attributable to postsynaptic alterations of intrinsic membrane properties by these agents. Concentrations of DHPG and CHPG that potentiated synaptic transmission did not affect $I-V$ relationships of CeA neurons. Neither a parallel shift nor a change of slope conductance of the $I-V$ curves was measured in CeA neurons (Fig. 6A,B). At high concentrations, however, DHPG and CHPG decreased the slope conductance significantly both in CeA neurons from arthritic rats and in control neurons (for details, see Fig. $6 A, B$ ). These data show that 


\section{A normal $\quad B$ arthritis}
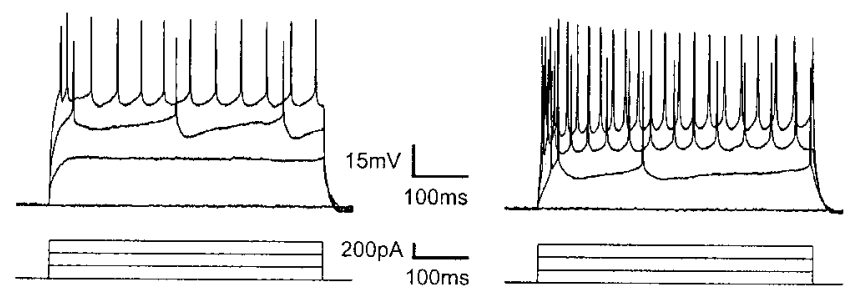

C

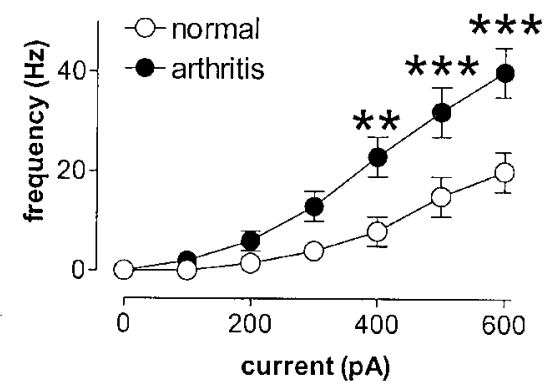

D normal
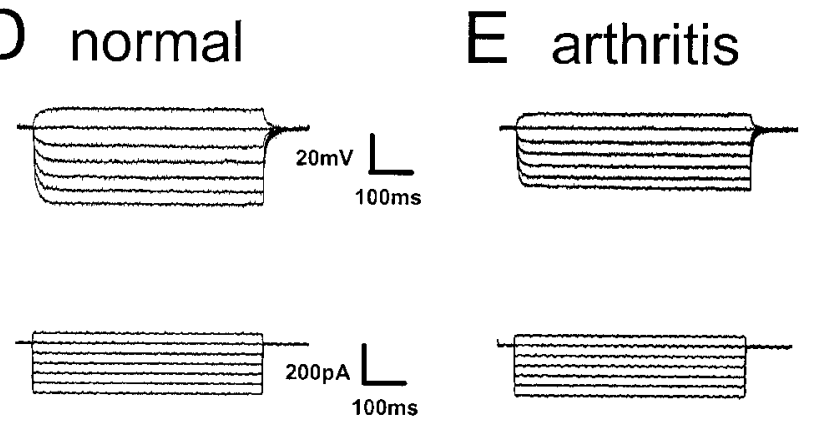

F

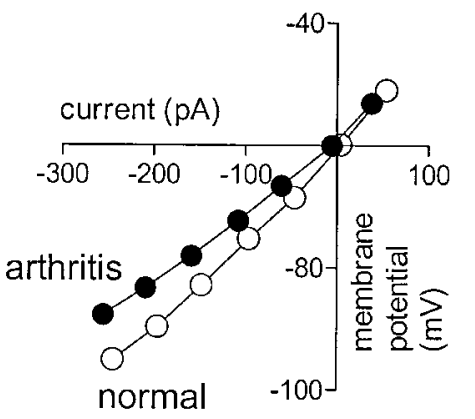

Figure 2. Enhanced action potential firing rate, lower spike threshold, and increased input resistance recorded in CeA neurons in the arthritis pain model compared with control neurons. $A, B$, Current-clamp recordings of depolarizations and action potentials (top traces) generated by direct current pulses of increasing magnitude ( $200 \mathrm{pA}$ steps, 500 msec duration; bottom traces) injected via the recording electrode in a CeA neuron from a normal rat $(A)$ and in a CeA neuron from an arthritic rat $6 \mathrm{hr}$ after induction of arthritis $(B)$. C, The action potential firing rate in CeA neurons in the arthritis pain model ( $n=21)$ was significantly $\left(p<0.0001 ; F_{(1.448)}=34.25\right.$; two-way ANOVA) increased compared with control CeA neurons $(n=45) .{ }^{* *} p<0.01$; ${ }^{* * *} p<0.001$; Bonferroni post-tests after the two-way ANOVA.D-F, Calculation of neuronal input resistance in the current-clamp mode. CeA neurons from arthritic rats $(E, F$, filled circles) had a lower input resistance than control CeA neurons $(D, F$, open circles). Input resistance was calculated from the slope of the linear portion of the $I-V$ curve $(F)$. $I-V$ curves were obtained by plotting steady-state voltage changes against the amplitudes of transient current pulses ( $500 \mathrm{msec}$ ) injected via the recording electrode in 50 pA increments from a holding potential of $-60 \mathrm{mV}(D, E)$.
BLA-CeA synapse

\section{A normal}
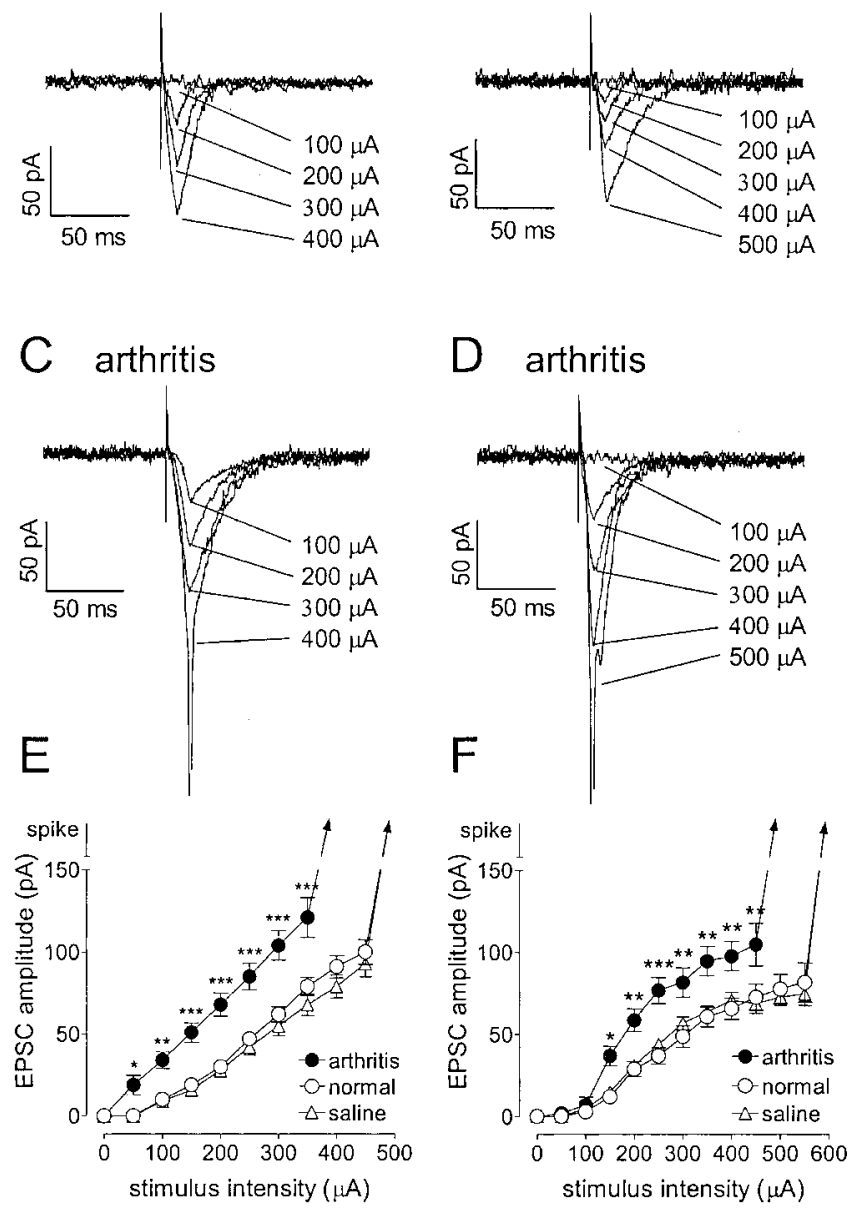

Figure 3. Enhanced synaptic transmission in the CeA in the arthritis pain model. Coronal brain slices containing the CeA were obtained from control (uninjected normal and salineinjected sham) rats and from rats with arthritis in the left knee ( $6-8 \mathrm{hr}$ after injection of kaolin/carrageenan). Whole-cell voltage-clamp recordings were made from neurons in the lateral capsular part of the CeA. Synaptic transmission was studied at two synaptic pathways in the $\mathrm{CeA}$, using electrical stimulation of afferent fibers from the parabrachial area $(\mathrm{PB} \rightarrow \mathrm{CeA}$ synapse) and from the basolateral amygdala (BLA $\rightarrow$ CeA synapse). Monosynaptic EPSCs were recorded, and input- output relationships were obtained by increasing the stimulus intensity in $50 \mu$ A steps and measuring the peak amplitudes of evoked EPSCS. $A-D$, Individual examples of one CeA neuron recorded in the brain slice from a normal rat $(A, B)$ and another CeA neuron from an arthritic rat ( $C, D ; 6 \mathrm{hr}$ after induction). $A, C$, At the $B L A \rightarrow$ CeA synapse, lower thresholds for EPSCS and orthodromic spike generation were recorded in arthritis. B, D, EPSCs evoked at the $\mathrm{PB} \rightarrow$ CeA synapse in arthritis had lower spike thresholds. E, F, Significantly altered inputoutput relationships in neurons from arthritic animals $(n=20)$ compared with control neurons ( $n=36$; normal uninjected rats, $n=26$; saline-injected shams, $n=10$ ), suggesting enhanced synaptic transmission at both the BLA $\rightarrow \mathrm{CeA}(E)$ and $\mathrm{PB} \rightarrow \mathrm{CeA}(F)$ synapses (two-way ANOVA followed by Bonferroni post-tests). ${ }^{*} p<0.05 ;{ }^{* *} p<0.01$; ${ }^{* * *} p<0.001$. Neurons were held at $-60 \mathrm{mV}$.

we were able to detect drug effects on membrane properties with the experimental approach we used in this study.

\section{Antagonists}

The results with mGluR1 and mGluR5 agonists suggest that the receptor sensitivity of mGluR1 is increased in arthritic animals. We next examined whether these receptors are involved in tonic regulation of synaptic transmission in CeA neurons under normal conditions and whether this modulation is enhanced in ar- 
A normal

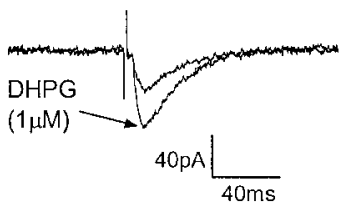

B arthritis
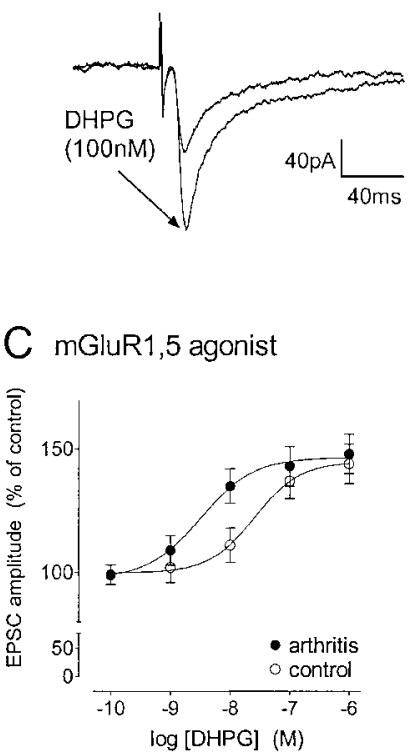
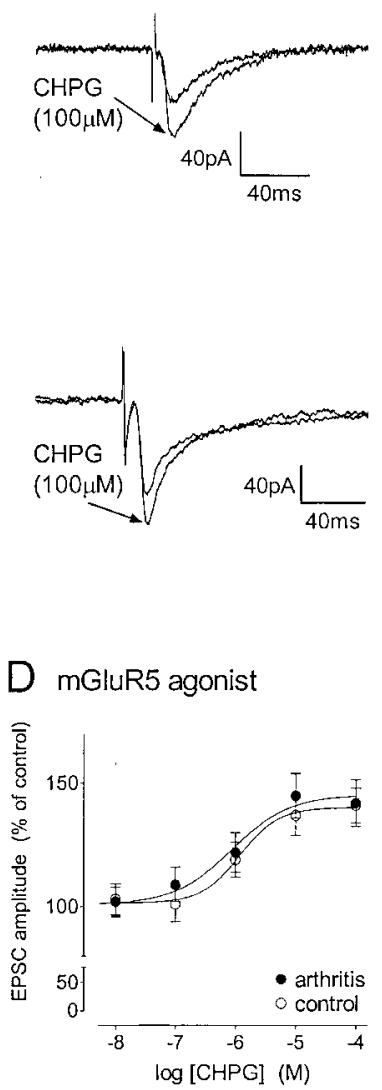

Figure 4. Group I mGluR agonists facilitate synaptic transmission in the amygdala. $A$, In one CeA neuron recorded in a brain slice from a normal rat, DHPG (1 $\mu$ m; mGluR1 and mGluR5 agonist) and CHPG (100 $\mu$ m; mGluR5 agonist) enhanced monosynaptic EPSCs at the PB $\rightarrow$ CeA synapse, suggesting the involvement of $\mathrm{mGluR5}$ in group I mGluR effects on normal transmission. $B$, In a CeA neuron recorded in a slice from an arthritic rat ( $7 \mathrm{hr}$ after induction), DHPG (100 $\mathrm{nm}$; note lower concentration than in $A$ ) but not CHPG became more potent in enhancing EPS(S. Each trace is the average of $8-10 \mathrm{EPSC}$ s recorded at $-60 \mathrm{mV}$. Drugs were applied by superfusion of the slice in ACSF for 8-10 min. Data shown were recorded at 8-10 min. C, D, Cumulative concentration-response relationships (see Materials and Methods) show the increased potency of DHPG but not CHPG on transmission at the PB $\rightarrow$ CeA synapse in arthritis $6-8 \mathrm{hr}$ after induction (DHPG, $n=11$; CHPG, $n=8$ ) compared with neurons from control rats (DHPG, $n=$ $12 ;$ CHPG, $n=9$ ), suggesting a change of mGluR1 rather than mGluR5 receptor sensitivity and function.

thritis. In CeA neurons recorded in brain slices from normal rats (see individual neuron in Fig. 7A), a selective mGluR5 antagonist, MPEP, inhibited monosynaptic EPSCs evoked at the $\mathrm{PB} \rightarrow \mathrm{CeA}$ and BLA $\rightarrow$ CeA synapses, whereas a selective mGluR1 antagonist, CPCCOEt, had no effect. In CeA neurons from arthritic animals, however, block of mGluR1 with CPCCOEt inhibited synaptic transmission (see individual example in Fig. 7B). Analysis of the concentration-response relationships showed that CPCCOEt (mGluR1 antagonist) (Fig. 7C) inhibited synaptic transmission at the $\mathrm{PB} \rightarrow$ CeA synapse in the arthritis pain model $\left(\mathrm{EC}_{50}, 94 \mathrm{~nm} ; n=9\right.$ neurons) (Fig. $7 C$, filled circles), whereas CPCCOEt had no significant effect on synaptic transmission under normal conditions; i.e., the slope of the concentrationresponse curve was not significantly different from zero $(p>$ $0.05 ; F_{(1,3)}=6.482 ; n=11$; linear regression analysis, Prism 3.0, GraphPad software) (Fig. 7C, open circles). A similar change of CPCCOEt effects was observed at the BLA $\rightarrow$ CeA synapse, although the antagonist was less potent $\left(\mathrm{EC}_{50}, 179 \mathrm{nM} ; n=9\right.$ neu-

\section{A normal $\quad B$ arthritis}
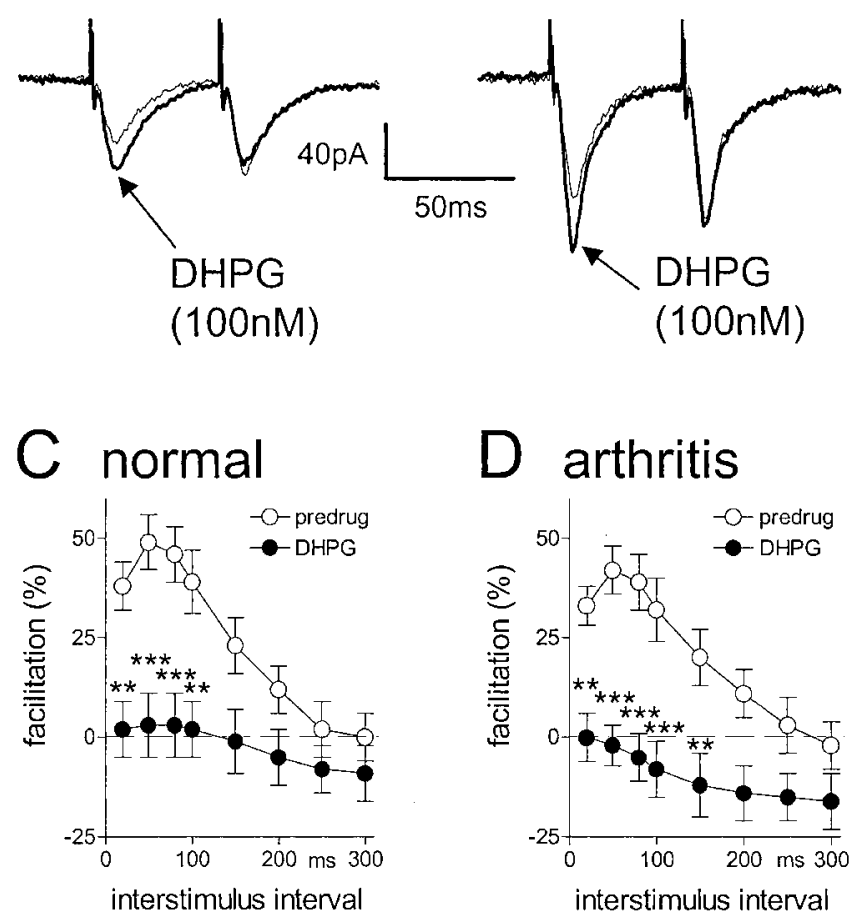

Figure 5. A group I $\mathrm{mGluR}$ agonist (DHPG) reduced PPF, indicating that enhanced presynaptic transmitter release contributed to the synaptic potentiation by DHPG. PPF (see Materials and Methods) was studied at the $\mathrm{PB} \rightarrow$ CeA synapse before and during application of DHPG. $A$, $B$, DHPG (100 nм; thick lines) reduced PPF in a control CeA neuron $(A)$ and in a CeA neuron from an arthritic rat $(B)$, whereas the amplitudes of the initial EPSCs were potentiated by DHPG as described before (Fig. 4). Neurons were recorded in the whole-cell voltage-clamp mode and held at $-60 \mathrm{mV}$. Each trace is the average of $8-10$ EPSCs. DHPG was applied by superfusion of the slice in ACSF for $10 \mathrm{~min}$. Data shown were recorded at $8-10 \mathrm{~min}$. C, D, PPF at the PB $\rightarrow$ CeA synapse is significantly reduced in the presence of DHPG in CeA neurons from normal rats $(n=$ 6) and in CeA neurons from arthritic rats $(n=5)$. Peak amplitudes were measured as the difference between the current level before the stimulus artifact and the peak of the EPSC. PPF was calculated as [(EPSC2 - EPSC1)/EPSC1] $\times 100$. Paired pulse EPSCS were evoked at a frequency of $0.1 \mathrm{~Hz} .{ }^{* *} p<0.01 ;{ }^{* * *} p<0.001$, Bonferroni post-tests after two-way ANOVA.

rons) than at the $\mathrm{PB} \rightarrow \mathrm{CeA}$ synapse (see above). The analysis of the raw data showed that block of mGluR1 by CPCCOEt reduced the increased EPSC amplitude in CeA neurons from arthritic rats to control levels measured in neurons from nonarthritic rats (Fig. $7 D$ ), suggesting that the increased EPSC component in enhanced synaptic transmission in the arthritis pain model involves mGluR1.

The comparison of the concentration-response relationships for MPEP (mGluR5 antagonist) (Fig. 7E) in normal and arthritic animals showed the concentration-dependent inhibition of synaptic transmission at the $\mathrm{PB} \rightarrow \mathrm{CeA}$ synapse in both experimental conditions without a significant change in potency or efficacy $\left(p>0.05 ; F_{(4,76)}=0.10\right.$; two-way ANOVA). The $\mathrm{EC}_{50}$ values for inhibitory effects of MPEP at the $\mathrm{PB} \rightarrow \mathrm{CeA}$ synapse were $28.3 \mathrm{nM}$ in control neurons $(n=10)$ and $27.7 \mathrm{nM}$ in arthritis $(n=9)$. MPEP was more potent at the BLA $\rightarrow$ CeA synapse in control neurons $\left(\mathrm{EC}_{50}, 11.4 \mathrm{nM} ; n=10\right)$ as well as in arthritis $\left(\mathrm{EC}_{50}, 10.1\right.$ nM; $n=9)$. The analysis of the raw data showed that the mGluR5 antagonist MPEP reduced a larger portion of the increased EPSC in arthritis than in control neurons; however, the MPEPinsensitive component of the EPSC also increased in arthritis 

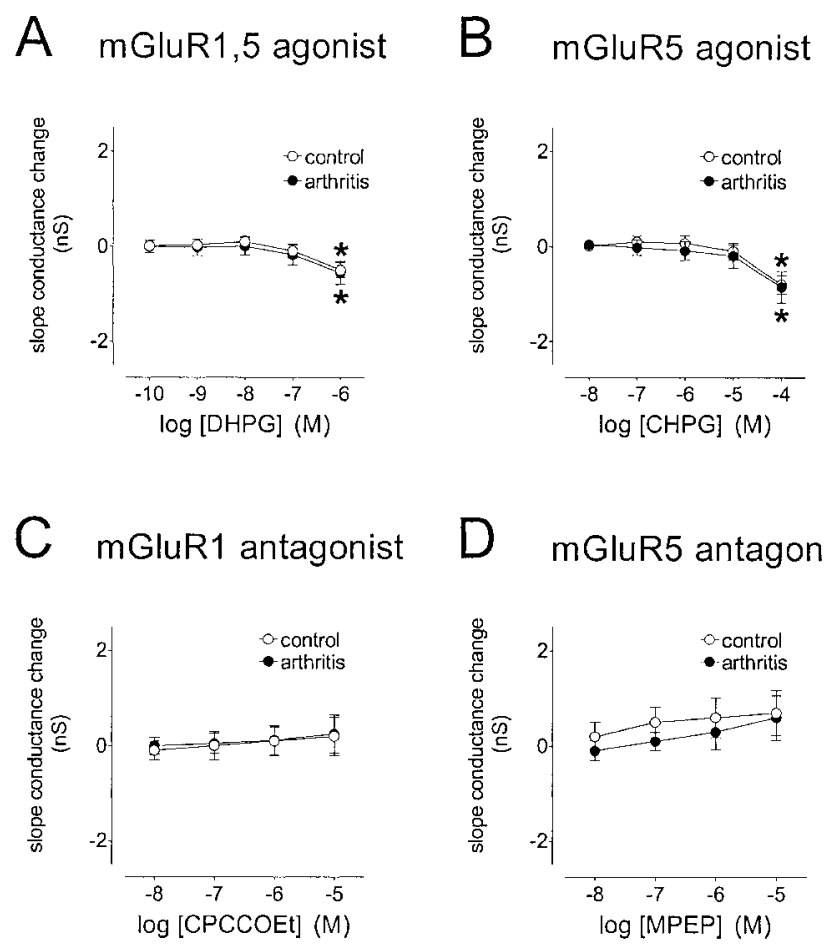

Figure 6. Low concentrations of the group I mGluR agonists DHPG ( $A$ ) and CHPG $(B)$ do not produce postsynaptic membrane effects on slope conductance in CeA neurons from arthritic rats (DHPG, $n=11 ;$ CHPG $n=8$ ) and in CeA neurons from control rats (DHPG, $n=12$; CHPG, $n=$ 9). At higher concentrations, however, DHPG $(1 \mu \mathrm{M})$ and $\mathrm{CHPG}(100 \mu \mathrm{M})$ significantly decreased the slope conductance both in CeA neurons from arthritic rats and in control neurons. Group I mGluR antagonists $(P C C O E t(C)$ and MPEP $(D)$ did not have postsynaptic membrane effects on slope conductance in control CeA neurons (CPCCOEt, $n=11 ; \mathrm{MPEP}, n=10)$ and in CeA neurons from arthritic animals (CPCCOEt, $n=9 ; \mathrm{MPEP}, n=9$ ). For each neuron, the slope conductance was calculated from the $I-V$ relationships in the presence and absence of the different drug concentrations. $I-V$ curves were constructed by plotting steady-state currents from voltageclamp recordings against membrane potential in the absence and presence of a particular drug. Whole-cell currents were elicited by a series of $400 \mathrm{msec}$ voltage steps $(-110$ to $-40 \mathrm{mV})$ from a holding potential of $-60 \mathrm{mV}$ in control ACSF and during drug application (after $11 \mathrm{~min}$ ). ${ }^{*} p<$ 0.05 , post hoc $t$ test after repeated measures ANOVA.

(Fig. 7F). The overall consequence is that the mGluR5dependent component of synaptic transmission remains unchanged in the arthritis pain model.

Neither antagonist had any significant postsynaptic effects on intrinsic membrane properties such as current-voltage relationships. There was no drug-induced change in slope conductance in CeA neurons from arthritic rats and in control CeA neurons (Fig. 6C,D).

These data suggest the intrinsic activation of mGluR5, but not mGluR1, in normal synaptic transmission and the additional involvement of mGluR1 in enhanced synaptic transmission in the arthritis pain model. This observation is consistent with the agonist studies (see above) that suggest the increased function of mGluR1 rather than mGluR5 in the arthritis pain model.

\section{Upregulation of $\mathrm{mGluR} 1$ and $\mathrm{mGluR} 5$ protein expression in the arthritis pain model}

The enhanced effects of mGluR1 agonists and antagonists in arthritis could be mediated by increased expression of mGluR1, increased sensitivity and activity of existent receptors, or both. To test whether arthritis caused increased expression of mGluR1 protein in the CeA, we performed quantitative Western blot analysis of mGluR1 and mGluR5 protein expression in the CeA. We
A normal
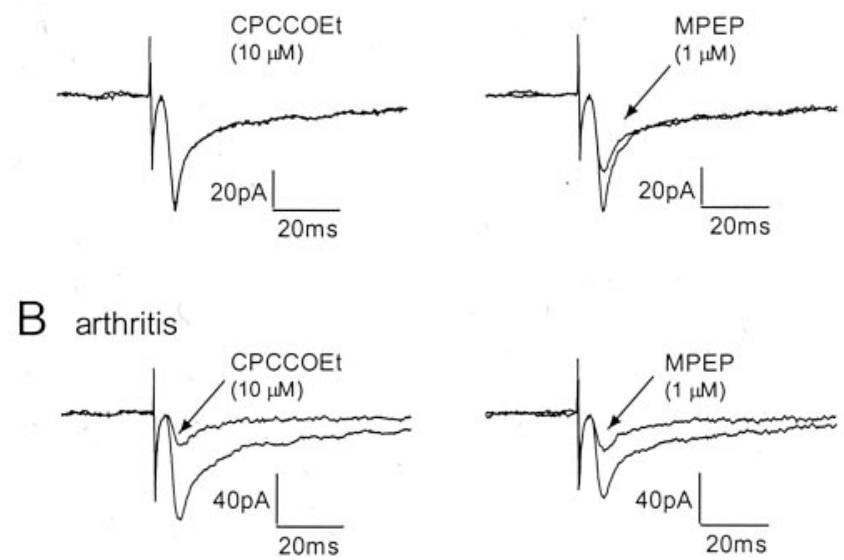

C

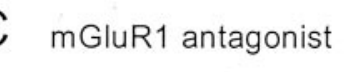

E mGluR5 antagonist

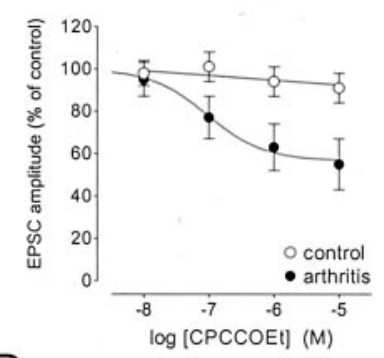

D
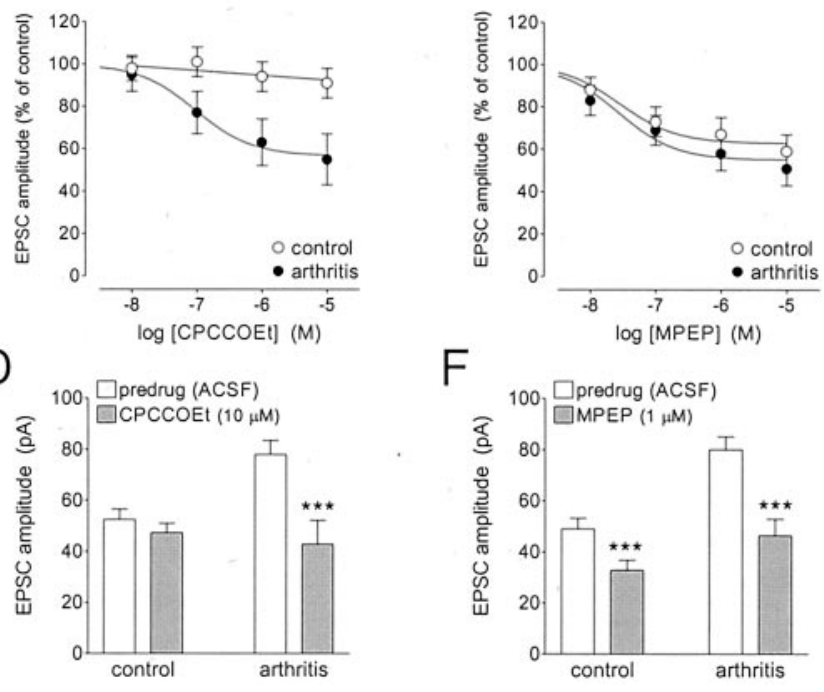

$\mathrm{F}$

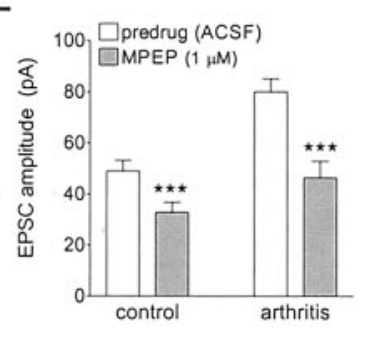

Figure 7. Differential changes of mGluR1-and mGluR5-mediated effects in the arthritis pain model. $A$, In a CeA neuron recorded in a brain slice from a normal rat, MPEP ( $1 \mu \mathrm{m}$; mGluR5 antagonist) inhibited synaptic transmission, whereas (PCCOEt (10 $\mu \mathrm{m}$; mGluR1 antagonist) had no effect. $B$, In a CeA neuron from an arthritic rat ( $6 \mathrm{hr}$ after induction), both CPCCOEt and MPEP inhibited synaptic transmission, suggesting a change in the endogenous activation of mGluR1 in the arthritis pain model. Each trace is the average of 8-10 monosynaptic EPSCs recorded at $-60 \mathrm{mV}$. Drugs were applied by superfusion of the slice in ACSF for at least $10 \mathrm{~min}$. Data shown were recorded at 10-12 min. C, CPCCOEt inhibited synaptic transmission in neurons from arthritic rats $\left(\mathrm{EC}_{50}, 94 \mathrm{~nm} ; n=9\right)$ but not in neurons from normal rats $(n=11)$, suggesting a change in the activation state of mGluR1 in the arthritis pain model. $D$, Analysis of the raw data (EPSC peak amplitude in picoamperes) shows that blocking of mGluR1 by CPCCOEt significantly reduced the increased EPSC amplitude in CeA neurons from arthritic rats to control levels measured in neurons from nonarthritic rats. $E$, The inhibitory effects of MPEP on synaptic transmission in CeA neurons were not significantly different in normal rats $\left(\mathrm{EC}_{50}, 28.3 \mathrm{~nm} ; n=10\right)$ and in arthritis ( $\mathrm{EC}_{50}, 27.7 \mathrm{~nm} ; n=9 ; p>0.05$; two-way ANOVA). $F$, Analysis of the raw data (picoamperes) shows that MPEP reduced a larger portion of the increased EPSC in arthritis than in control neurons; however, the MPEP-insensitive component of the EPSC also increased in arthritis. ${ }^{* *} p<0.001$; unpaired $t$ test.

detected high levels of mGluR5 but little mGluR1 under normal conditions (Fig. 8). In the CeA from arthritic animals (6-8 hr after induction), however, significantly more expression of mGluR1 was detected as well as an increased expression of mGluR5. Densitometric analysis of mGluR1a and mGluR5 immunoreactivity showed a significant increase of mGluR1 and mGluR5 expression in the contralateral CeA of arthritic rats and 

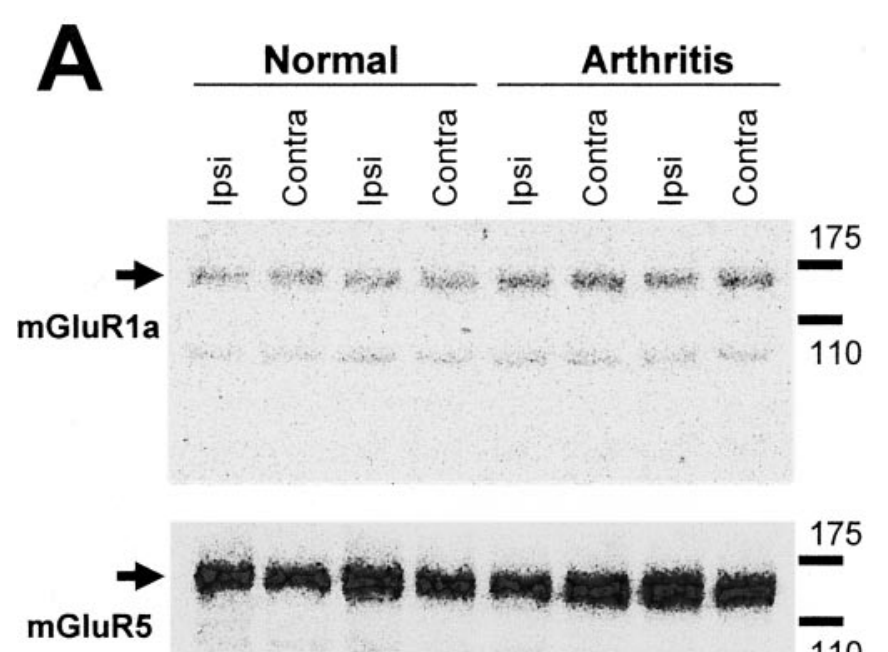

110

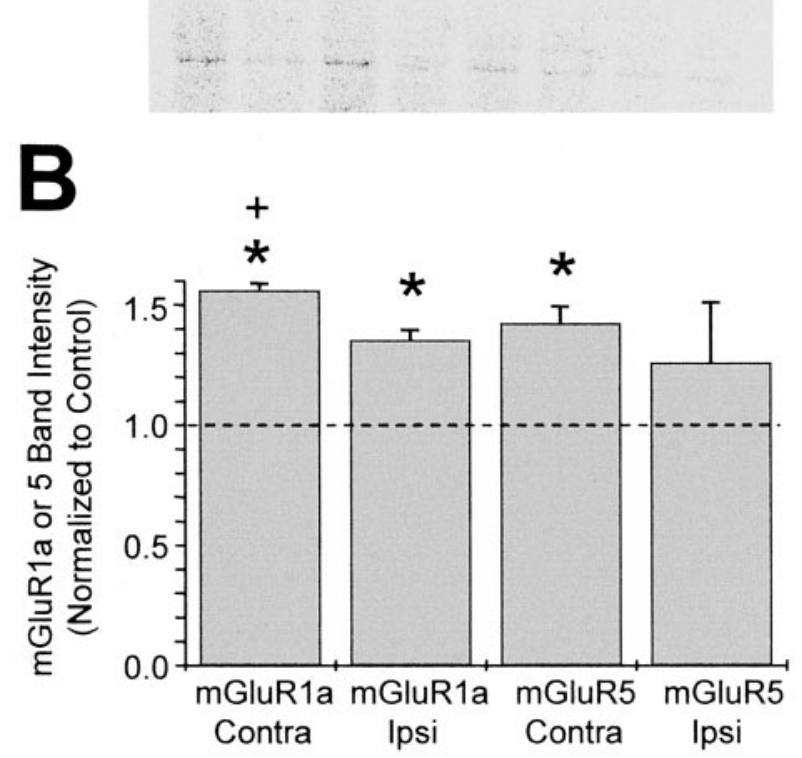

Figure 8. Upregulation of mGluR1 and mGluR5 in the amygdala in the arthritis pain model. Group I mGluR1 and mGluR5 expression increased in the amygdala 5-6 hr after kaolin/ carrageenan-induced arthritis in the knee. A, Top panel, mGluR1a immunoblot of amygdala (CeA) membranes from normal and arthritic rats; the $\sim 150 \mathrm{kDa}$ band is mGluR1a, whereas the bottom band probably represents a proteolytic fragment or cross-reactive protein. Bottom panel, mGluR5 immunoblot of amygdala (CeA) membranes from normal and arthritic rats; the $\sim 150 \mathrm{kDa}$ band represents mGluR5 immunoreactivity. $B$, Densitometry of mGluR1a and mGluR5 immunoreactivity suggests an increase in group I mGluR expression in arthritic rats with a greater increase in the contralateral amygdala $\left(n=3\right.$ in duplicate; ${ }^{+} p<0.05$ when compared with the ipsilateral side with paired $t$ test; ${ }^{*} p<0.05$ when compared with normal rats using a one-sample $t$ test).

a significant increase in mGluR1, but not mGluR5, in the ipsilateral CeA (Fig. $8 B ; n=3$ in duplicate; ${ }^{\star} p<0.05$, arthritis compared with normal control using a one-sample $t$ test; ${ }^{+} p<0.05$, contralateral CeA compared with the ipsilateral side in arthritis with paired $t$ test). These results strongly suggest that the increased effects of mGluR1 agonists in arthritis is attributable to increased expression of mGluR1 protein in the CeA.

\section{Discussion}

This study is the first to analyze synaptic plasticity and underlying mechanisms in the amygdala in a model of prolonged pain. We show that the amygdala undergoes dramatic neuroplastic changes in a well established model of arthritic pain arising from a localized inflammation of one knee joint (Neugebauer et al., 1993, 1994, 1995, 1996). Neuroplasticity is manifested as altered excitability and enhanced synaptic transmission in CeA neurons recorded in brain slices in vitro in the arthritis pain state induced in vivo. We also demonstrate the contribution of enhanced function and expression of presynaptic mGluR1 within the CeA to this plasticity.

Synaptic plasticity in the amygdala, particularly the lateral and basolateral nuclei (LA and BLA), is involved in a variety of behavioral modifications and disorders, including models of epilepsy, drug addiction, conditioned fear, and associative learning (Rainnie et al., 1992; McKernan and Shinnick-Gallagher, 1997; Neugebauer et al., 1997a; Davis, 1998; Huang and Kandel, 1998; Post et al., 1998; Maren, 1999; LeDoux, 2000; Lin et al., 2000, 2001; Rolls, 2000; Bauer et al., 2001; Blair et al., 2001). The role of the amygdala in persistent and chronic pain is not clear. A behavioral study was unable to show a significant reduction of pain responses in the formalin test (Manning, 1998), but long-term increases of regional blood flow were detected in the amygdala in a neuropathic pain model (Paulson et al., 2002).

We found several long-lasting physiological changes in the $\mathrm{CeA}$ in the arthritis pain model. The nociceptive-specific inputs from the pontine PB area were potentiated in CeA neurons from arthritic rats compared with controls. Thus, incoming nociceptive signals would generate enhanced responses in the amygdala. In addition, we also observed significant enhancement of synaptic transmission at the $\mathrm{BLA} \rightarrow \mathrm{CeA}$ synapse, which provides highly processed polymodal information. This is consistent with the integrative role of the amygdala in the complex emotional behavior in response to aversive events (pain). The enhanced transmission was accompanied by changes in membrane properties of CeA neurons (decreased input resistance and increased slope conductance), suggesting tonic activation of ion channels during prolonged pain. The overall enhanced excitability of CeA neurons in the arthritic pain model is also reflected in the lower threshold for action potentials generated by intracellular current injections.

Importantly, changes in synaptic transmission and intrinsic membrane properties of CeA neurons in the arthritis pain model differ from those observed in other models of amygdala plasticity. In a model of drug addiction, chronic cocaine treatment in vivo also enhanced CeA excitatory synaptic transmission but altered the gain of CeA synapses differently than in the present study (Neugebauer et al., 2000). Furthermore, membrane properties of CeA neurons were altered differently in the chronic cocaine model than in our arthritis pain model in that the lower input resistance and increased slope conductance resulted in a hyperpolarized membrane potential (Neugebauer et al., 2000) rather than a depolarization as observed here, suggesting that different ionic mechanisms underlie the excitability changes. In contrast to the arthritis pain and chronic cocaine models, enhanced synaptic transmission in the kindling model of epilepsy was not accompanied by intrinsic membrane property changes of CeA and BLA neurons (Neugebauer et al., 1997a, 2000). Similarly, in the fearconditioning model, synaptic transmission in LA neurons was enhanced in the absence of intrinsic membrane property changes (McKernan and Shinnick-Gallagher, 1997). These differential plastic changes in the amygdala suggest specificity in different models of behavioral plasticity.

Our results show that both input to and output from the CeA are enhanced during arthritis-induced prolonged pain. The altered input to CeA neurons is reflected in the enhancement of synaptic transmission, and the increased output will result from 
the enhanced excitability of CeA neurons in arthritis. As the output nucleus for major amygdala functions, the CeA with its laterocapsular division, also termed the "nociceptive amygdala" because of its high content of nociceptive neurons (Bourgeais et al., 2001; Neugebauer and Li, 2002), is well positioned to contribute to aversive and anxiogenic reactions to noxious stimuli, to participate in autonomic and endocrine aspects of emotional pain behavior, and to influence cortical sensory processing and forebrain mechanisms of pain modulation (Willis, 1991; Casey, 1999; Gallagher and Schoenbaum, 1999; Fields, 2000; LeDoux, 2000; Bourgeais et al., 2001).

The electrophysiological changes of CeA neurons were closely paralleled by changes in the sensitivity of these cells to the group I mGluR agonist DHPG. DHPG potentiated synaptic transmission at the $\mathrm{PB} \rightarrow \mathrm{CeA}$ synapse, and arthritis produced a significant increase in the potency of DHPG. Interestingly, the effects of the selective mGluR5 agonist CHPG were unaltered. These data suggest that, under normal conditions, the facilitation of synaptic transmission by group I mGluR agonists is mediated through mGluR5, whereas the enhanced effects of group I mGluR activation in arthritis involve recruitment or enhanced coupling of mGluR1. Similar but less pronounced changes of DHPG effects in arthritis were measured at the $\mathrm{BLA} \rightarrow \mathrm{CeA}$ synapse, suggesting a closer association of mGluR1 with the nociceptive $\mathrm{PB} \rightarrow \mathrm{CeA}$ synapse than with the polymodal BLA $\rightarrow$ CeA synapse. Our study is the first to analyze the role of group I mGluR subtypes on synaptic transmission at the $\mathrm{PB} \rightarrow \mathrm{CeA}$ and $\mathrm{BLA} \rightarrow \mathrm{CeA}$ synapses in the amygdala. Although previous studies reported inhibition of synaptic transmission by DHPG, there is also good evidence for enhanced transmitter release by group I mGluRs and facilitation of fast synaptic transmission by mGluRs (Anwyl 1999; Cartmell and Schoepp, 2000). The effects of group I mGluR activation can differ with different brain areas, synapses, systems, and pathways studied and therefore need to be analyzed in each instance. Importantly, synaptic potentiation by group I mGluRs in the CeA involves enhanced presynaptic transmitter release, as evidenced by our PPF data (Fig. 5) and the lack of drug effects on intrinsic membrane properties (Fig. 6). PPF has been used in the amygdala before to analyze presynaptic mechanisms of synaptic plasticity in the fear-conditioning model (McKernan and ShinnickGallagher, 1997).

Our studies using selective antagonists suggest increased mGluR1 function in the arthritis pain model. Under normal conditions, fast synaptic transmission was partially inhibited by the selective mGluR5 antagonist MPEP, whereas CPCCOEt, a selective mGluR1 antagonist, had no effect at the concentrations used in this study. However, in neurons from arthritic animals, the mGluR1 antagonist significantly reduced fast synaptic transmission. Importantly, CPCCOEt reduced the increased EPSC amplitude in neurons from arthritic animals to the level of control neurons. Although MPEP reduced a larger portion of the increased EPSC in arthritis than in control neurons, the MPEPinsensitive component of the EPSC also increased in arthritis; therefore, the mGluR5-dependent proportion of synaptic transmission would remain unchanged in the arthritis pain model.

These results suggest that synaptic transmission in the arthritis pain model involves mGluR1 activation. Alternatively, basal extracellular levels of glutamate may increase in arthritis to a concentration sufficient to activate mGluRs, allowing antagonists to reduce transmission. In other brain regions, activation of group I mGluRs can depolarize cells by activation of a variety of $\mathrm{Ca}^{2+}$-dependent and -independent nonselective inward cationic currents (Conn and Pin, 1997; Anwyl, 1999; Neugebauer, 2001a).
This could explain the decrease in input resistance, increased slope conductance, and depolarization we observed in CeA neurons from arthritic animals. In the present study, however, mGluR effects were attributable to presynaptic mechanisms in CeA neurons from control or arthritic animals, suggesting that tonic activation of these mGluRs by ambient glutamate cannot directly account for the alterations in membrane properties. These data also suggest that synaptic plasticity occurs, at least in part, independently of intrinsic membrane property changes.

In addition to enhanced endogenous activation, the following mechanisms could explain the enhanced mGluR1 function in CeA neurons in the arthritis pain model: increased receptor expression, enhanced receptor sensitivity, decreased desensitization, and altered coupling to signal transduction pathways. We found that mGluR1 protein expression was significantly increased in the CeA in arthritic animals compared with controls, suggesting that the enhanced mGluR1 function reflects either increased production of mGluR1 mRNA or protein or increased stability of the protein. We also observed a significant increase in mGluR5 levels in arthritic animals, but our electrophysiological and pharmacological data suggest that the proportion of mGluR5-dependent enhanced synaptic transmission is not changed from that in the arthritis pain model. The reason why the increase of mGluR5 does not seem to translate into functional significance is not clear, but it is possible that the maximum contribution of mGluR5 to synaptic transmission is accomplished with the levels of receptor expression measured under normal conditions, and the increase in arthritis would not translate into functional changes ("ceiling effect"). Alternatively, the increase in mGluR5 levels may occur in cells other than those involved in our recordings.

In summary, this study is the first to analyze electrophysiological, pharmacological, and biochemical changes in the amygdala in a model of persistent pain arising from a monoarthritic lesion. We demonstrate here that the potentiation of synaptic transmission and enhanced neuronal excitability in the amygdala is preserved in an in vitro preparation that is disconnected from the site of arthritic injury induced in vivo, suggesting that this plasticity is maintained independent of continuous afferent inputs. This plasticity involves increased presynaptic group I mGluR function, which reflects an underlying increase in mGluR1 expression in the CeA.

\section{References}

Aggleton JP (2000) The amygdala: a functional analysis. Oxford: Oxford UP.

Alheid GF, De Olmos JS, Beltramino CA (1995) Amygdala and extended amygdala. In: The rat nervous system (Paxinos G, ed), pp 495-578. San Diego: Academic.

Anwyl R (1999) Metabotropic glutamate receptors: electrophysiological properties and role in plasticity. Brain Res Brain Res Rev 29:83-120.

Bauer EP, LeDoux JE, Nader K (2001) Fear conditioning and LTP in the lateral amygdala are sensitive to the same stimulus contingencies. Nat Neurosci 4:687-688.

Bernard J-F, Bandler R (1998) Parallel circuits for emotional coping behaviour: new pieces in the puzzle. J Comp Neurol 401:429-436.

Bernard J-F, Huang GF, Besson JM (1992) Nucleus centralis of the amygdala and the globus pallidus ventralis: electrophysiological evidence for an involvement in pain processes. J Neurophysiol 68:551-569.

Bernard JF, Alden M, Besson JM (1993) The organization of the efferent projections from the pontine parabrachial area to the amygdaloid complex: a Phaseolus vulgaris leucoagglutinin (PHA-L) study in the rat. J Comp Neurol 329:201-229.

Blair HT, Schafe GE, Bauer EP, Rodrigues SM, LeDoux JE (2001) Synaptic plasticity in the lateral amygdala: a cellular hypothesis of fear conditioning. Learn Mem 8:229-242. 
Blanton MG, Lo Turco JJ, Kriegstein AR (1989) Whole cell recording from neurons in slices of reptilian and mammalian cerebral cortex. J Neurosci Methods 30:203-210.

Borszcz GS (1999) Differential contributions of medullary, thalamic, and amygdaloid serotonin to the antinociceptive action of morphine administered into the periaqueductal gray: a model of morphine analgesia. Behav Neurosci 113:612-631.

Bourgeais L, Gauriau C, Bernard J-F (2001) Projections from the nociceptive area of the central nucleus of the amygdala to the forebrain: a PHA-L study in the rat. Eur J Neurosci 14:229-255.

Buritova J, Besson JM, Bernard J-F (1998) Involvement of the spinoparabrachial pathway in inflammatory nociceptive processes: a c-Fos protein study in the awake rat. J Comp Neurol 397:10-28.

Cahill L (1999) A neurobiological perspective on emotionally influenced, long-term memory. Semin Clin Neuropsychol 4:266-273.

Calvino B, Levesque G, Besson JM (1982) Possible involvement of the amygdaloid complex in morphine analgesia as studied by electrolytic lesions in rats. Brain Res 233:221-226.

Cartmell J, Schoepp DD (2000) Regulation of neurotransmitter release by metabotropic glutamate receptors. J Neurochem 75:889-907.

Casey KL (1999) Forebrain mechanisms of nociception and pain: analysis through imaging. Proc Natl Acad Sci USA 96:7668-7674.

Charpentier J (1967) Modifications de la réaction à la douleur provoquées par diverses lésions cérébrales, et leurs effets sur la sensibilitè á la morphine. Psychopharmacologia 11:95-121.

Conn PJ, Pin JP (1997) Pharmacology and functions of metabotropic glutamate receptors. Annu Rev Pharmacol Toxicol 37:205-237.

Davidson RJ, Abercrombie H, Nitschke JB, Putnam K (1999) Regional brain function, emotion and disorders of emotion. Curr Opin Neurobiol 9:228-234.

Davis M (1998) Anatomic and physiologic substrates of emotion in an animal model. J Clin Neurophysiol 15:378-387.

Dodt HU, Zieglgansberger W (1990) Visualizing unstained neurons in living brain slices by infrared DIC-videomicroscopy. Brain Res 537:333-336.

Dodt HU, Zieglgansberger W (1998) Visualization of neuronal form and function in brain slices by infrared videomicroscopy. Histochem J 30:141-152.

Doron NN, LeDoux JE (1999) Organization of projections to the lateral amygdala from auditory and visual areas of the thalamus in the rat. J Comp Neurol 412:383-409.

Fields HL (2000) Pain modulation: expectation, opioid analgesia and virtual pain. Prog Brain Res 122:245-253.

Fox RJ, Sorenson CA (1994) Bilateral lesions of the amygdala attenuate analgesia induced by diverse environmental challenges. Brain Res 648:215-221.

Fundytus ME (2001) Glutamate receptors and nociception: implications for the drug treatment of pain. CNS Drugs 15:29-58.

Gallagher M, Schoenbaum G (1999) Functions of the amygdala and related forebrain areas in attention and cognition. Ann NY Acad Sci 877:397-411.

Gasparini F, Kuhn R, Pin JP (2002) Allosteric modulators of group I metabotropic glutamate receptors: novel subtype-selective ligands and therapeutic perspectives. Curr Opin Pharmacol 2:43-49.

Harrigan EA, Magnuson DJ, Thunstedt GM, Gray TS (1994) Corticotropin releasing factor neurons are innervated by calcitonin gene-related peptide terminals in the rat central amygdaloid nucleus. Brain Res Bull 33:529-534.

Helmstetter FJ (1992) The amygdala is essential for the expression of conditional hypoalgesia. Behav Neurosci 106:518-528.

Holmes KH, Keele NB, Shinnick-Gallagher P (1996) Loss of mGluRmediated hyperpolarizations and increase in mGluR depolarizations in basolateral amygdala neurons in kindling-induced epilepsy. J Neurophysiol 76:2808-2812.

Huang YY, Kandel ER (1998) Postsynaptic induction and PKA-dependent expression of LTP in the lateral amygdala. Neuron 21:169-178.

Jasmin L, Burkey AR, Card JP, Basbaum AI (1997) Transneuronal labeling of a nociceptive pathway, the spino-(trigemino-)parabrachio-amygdaloid, in the rat. J Neurosci 17:3751-3765.

Jurgens U (1982) Amygdalar vocalization pathways in the squirrel monkey. Brain Res 241:189-196.

Jurgens U, Maurus M, Ploog D, Winter P (1967) Vocalization in the squirrel monkey (Saimiri sciureus) elicited by brain stimulation. Exp Brain Res 4:114-117.

Karim F, Bhave G, Gereau RW (2001) Metabotropic glutamate receptors on peripheral sensory neuron terminals as targets for the development of novel analgesics. Mol Psychol 6:615-617.

Keele NB, Zinebi F, Neugebauer V, Shinnick-Gallagher P (2000) Epileptogenesis up-regulates metabotropic glutamate receptor activation of sodiumcalcium exchange current in the amygdala. J Neurophysiol 83:2458-2462.

LeDoux JE (2000) Emotion circuits in the brain. Annu Rev Neurosci 23:155-184.

LeDoux JE, Cicchetti P, Xagoraris A, Romanski LM (1990) The lateral amygdaloid nucleus: sensory interface of the amygdala in fear conditioning. J Neurosci 10:1062-1069.

Lin CH, Yeh SH, Lin CH, Lu KT, Leu TH, Chang WC, Gean PW (2001) A role for the PI-3 kinase signaling pathway in fear conditioning and synaptic plasticity in the amygdala. Neuron 31:841-851.

Lin HC, Wang SJ, Luo MZ, Gean PW (2000) Activation of group II metabotropic glutamate receptors induces long-term depression of synaptic transmission in the rat amygdala. J Neurosci 20:9017-9024.

Linke R, De Lima AD, Schwegler H, Pape HC (1999) Direct synaptic connections of axons from superior colliculus with identified thalamoamygdaloid projection neurons in the rat: possible substrates of a subcortical visual pathway to the amygdala. J Comp Neurol 403:158-170.

Maier SF, Grahn RE, Kalman BA, Sutton LC, Wiertelak EP, Watkins LR (1993) The role of the amygdala and dorsal raphe nucleus in mediating the behavioral consequences of inescapable shock. Behav Neurosci 107:377-388.

Manning BH (1998) A lateralized deficit in morphine antinociception after unilateral inactivation of the central amygdala. J Neurosci 18:9453-9470.

Manning BH, Merin NM, Meng ID, Amaral DG (2001) Reduction in opioid- and cannabinoid-induced antinociception in rhesus monkeys after bilateral lesions of the amygdaloid complex. J Neurosci 21:8238-8246.

Maren S (1999) Long-term potentiation in the amygdala: a mechanism for emotional learning and memory. Trends Neurosci 22:561-567.

Martin SJ, Grimwood PD, Morris RG (2000) Synaptic plasticity and memory: an evaluation of the hypothesis. Annu Rev Neurosci 23:649-711.

Masugi M, Yokoi M, Shigemoto R, Muguruma K, Watanabe Y, Sansig G, van der Putten H, Nakanishi S (1999) Metabotropic glutamate receptor subtype 7 ablation causes deficit in fear response and conditioned taste aversion. J Neurosci 19:955-963.

McKernan MG, Shinnick-Gallagher P (1997) Fear conditioning induces a lasting potentiation of synaptic currents in vitro. Nature 390:607-611.

Min SS, Han JS, Kim YI, Na HS, Yoon YW, Hong SK, Han HC (2001) A novel method for convenient assessment of arthritic pain in voluntarily walking rats. Neurosci Lett 308:95-98.

Nader K, Majidishad P, Amorapanth P, LeDoux JE (2001) Damage to the lateral and central, but not other, amygdaloid nuclei prevents the acquisition of auditory fear conditioning. Learn Mem 8:156-163.

Neugebauer V (2001a) Metabotropic glutamate receptors: novel targets for pain relief. Expert Rev Neurotherapeutics 1:207-224.

Neugebauer V (2001b) Peripheral metabotropic glutamate receptors: fight the pain where it hurts. Trends Neurosci 24:550-552.

Neugebauer V (2002) Metabotropic glutamate receptors: important modulators of nociception and pain behavior. Pain 98:1-8.

Neugebauer V, Carlton SM (2002) Peripheral metabotropic glutamate receptors as drug targets for pain relief. Expert Opin Ther Targets 6:1-13.

Neugebauer V, Li W (2002) Processing of nociceptive mechanical and thermal information in central amygdala neurons with knee-joint input. J Neurophysiol 87:103-112.

Neugebauer V, Schaible HG (1990) Evidence for a central component in the sensitization of spinal neurons with joint input during development of acute arthritis in cat's knee. J Neurophysiol 64:299-311.

Neugebauer V, Schaible HG, Schmidt RF (1989) Sensitization of articular afferents to mechanical stimuli by bradykinin. Eur J Neurosci 415:330-335.

Neugebauer V, Lucke T, Schaible HG (1993) N-Methyl-D-aspartate (NMDA) and non-NMDA receptor antagonists block the hyperexcitability of dorsal horn neurons during development of acute arthritis in rat's knee joint. J Neurophysiol 70:1365-1377.

Neugebauer V, Lucke T, Schaible HG (1994) Requirement of metabotropic glutamate receptors for the generation of inflammation-evoked hyperexcitability in rat spinal cord neurons. Eur J Neurosci 6:1179-1186.

Neugebauer V, Weiretter F, Schaible HG (1995) Involvement of substance P and neurokinin-1 receptors in the hyperexcitability of dorsal horn neurons during development of acute arthritis in rat's knee joint. J Neurophysiol 73:1574-1583. 
Neugebauer V, Rumenapp P, Schaible HG (1996) The role of spinal neurokinin-2 receptors in the processing of nociceptive information from the joint and in the generation and maintenance of inflammation-evoked hyperexcitability of dorsal horn neurons in the rat. Eur J Neurosci 8:249-260.

Neugebauer V, Keele NB, Shinnick-Gallagher P (1997a) Epileptogenesis in vivo enhances the sensitivity of inhibitory presynaptic metabotropic glutamate receptors in basolateral amygdala neurons in vitro. J Neurosci 17:983-995.

Neugebauer V, Keele NB, Shinnick-Gallagher P (1997b) Loss of long-lasting potentiation mediated by group III mGluRs in amygdala neurons in kindling-induced epileptogenesis. J Neurophysiol 78:3475-3478.

Neugebauer V, Zinebi F, Russell R, Gallagher JP, Shinnick-Gallagher P (2000) Cocaine and kindling alter the sensitivity of group II and III metabotropic glutamate receptors in the central amygdala. J Neurophysiol 84:759-770.

Paulson PE, Casey KL, Morrow TJ (2002) Long-term changes in behavior and regional cerebral blood flow associated with painful peripheral mononeuropathy in the rat. Pain 95:31-40.

Paxinos G, Watson C (1998) The rat brain in stereotaxic coordinates. New York: Academic.

Pitkanen A, Savander V, LeDoux JE (1997) Organization of intraamygdaloid circuitries in the rat: an emerging framework for understanding functions of the amygdala. Trends Neurosci 20:517-523.

Post RM, Weiss SR, Li H, Smith MA, Zhang LX, Xing G, Osuch EA, McCann UD (1998) Neural plasticity and emotional memory. Dev Psychopathol 10:829-855.

Rainnie DG, Asprodini EK, Shinnick-Gallagher P (1992) Kindling-induced long-lasting changes in synaptic transmission in the basolateral amygdala. J Neurophysiol 67:443-454.
Rasia-Filho AA, Londero RG, Achaval M (2000) Functional activities of the amygdala: an overview. J Psychiatry Neurosci 25:14-23.

Robakiewicz P, Ryder EF (2000) Statistics: detecting differences among groups. In: Current protocols in protein science (Chandra VB, Leondar SA, eds), pp A.3G.1-A.3G.22. New York: Wiley.

Rolls ET (2000) Memory systems in the brain. Annu Rev Psychol 51:599-630.

Schneider F, Habel U, Holthusen H, Kessler C, Posse S, Muller-Gartner HW, Arndt JO (2001) Subjective ratings of pain correlate with subcorticallimbic blood flow: an MRI study. Neuropsychobiology 43:75-85.

Shi C, Davis M (1999) Pain pathways involved in fear conditioning measured with fear-potentiated startle: lesion studies. J Neurosci 19:420-430.

Smith Y, Pare JF, Pare D (2000) Differential innervation of parvalbuminimmunoreactive interneurons of the basolateral amygdaloid complex by cortical and intrinsic inputs. J Comp Neurol 416:496-508.

Tershner SA, Helmstetter FJ (2000) Antinociception produced by mu opioid receptor activation in the amygdala is partly dependent on activation of mu opioid and neurotensin receptors in the ventral periaqueductal gray. Brain Res 865:17-26.

Varney M, Gereau RW (2002) Metabotropic glutamate receptor involvement in models of acute and persistent pain: prospect for the development of novel analgesics. Curr Drug Targets CNS Neurol Dis 1:215-225.

Wang SJ, Gean PW (1999) Long-term depression of excitatory synaptic transmission in the rat amygdala. J Neurosci 19:10656-10663.

Watkins LR, Wiertelak EP, McGorry M, Martinez J, Schwartz B, Sisk D, Maier SF (1998) Neurocircuitry of conditioned inhibition of analgesia: effects of amygdala, dorsal raphe, ventral medullary, and spinal cord lesions on antianalgesia in the rat. Behav Neurosci 112:360-378.

Willis WD (1991) Role of the forebrain in nociception. Prog Brain Res $87: 1-12$. 